\section{AKADEMOS}

ISSN: $1995-4743$

Año 11 Vol. 1, n. 28 Enero-Junio 2017

AKADEMOS es una revista semestral. De amplio espacio editorial, para la publicación de trabajos inéditos de investigación, artículos de análisis, reseñas y opinión, en los distintos tópicos de las ciencias, la tecnología las artes y la cultura.

\title{
Análisis de la reforma al sistema de ahorro para pensiones*
}

Francisco Sorto Rivas

Docente de la Facultad de Posgrados y Educación Continúa, Máster en Economía y Máster en Dirección y Gestión de Planes y Fondos de Pensiones

fran.sorto@gmail.com

\section{Resumen}

El presente trabajo consiste en el análisis de la reciente reforma a la Ley del SAP, aprobada mediante el Decreto Legislativo 787, del 28 de septiembre de este año, 2017.

La denominada Reforma Integral de Pensiones redujo el valor de las prestaciones del SAP, aliviando con ello la presión existente sobre las finanzas públicas y preservando, a la vez, la administración privada de los ahorros para el retiro de los trabajadores.

En los medios de comunicación se han destacado las virtudes del consenso logrado para reformar la Ley del SAP, argumentan- do que con ello se viabilizarían, luego, otro tipo de acuerdos de nación, particularmente, en material fiscal.

De las reiteradas declaraciones se desprendería que todos los actores relevantes a la problemática han ganado con la reforma, tanto el Gobierno, los operadores del sistema y hasta los trabajadores. ¿Pero cómo puede ser posible esto?

En este breve análisis se mostrará cómo mediante la reforma de pensiones se trasladó

* $\quad$ Agradezco a la señora Cristina de Chávez por su apoyo para la redacción de este artículo. 
cerca del $50 \%$ de las obligaciones que tenía el Estado con el sistema, a los afiliados activos del SAP y, que además, redujo las obligaciones que tenía con otros afiliados al SAP, tanto activos como pasivos, identificados mediante el apelativo de "optados", por pertenecer a una franja etaria determinada cuando entró en operaciones el actual sistema de contribución definida, en abril de 1998.

Hay muchos cambios en la Ley, pero lo esencial de la reforma denominada integral, fue la extinción de obligaciones fiscales, preservando la administración privada del ahorro para el retiro.

Cabe aclarar que muchos de esos cambios carecen de fundamentación doctrinaria desde la perspectiva de la Seguridad Social y por ende, tienden a aumentar la vulnerabilidad de la población afiliada al SAP, en vez de mitigarla.

Estoy seguro que, en caso de haberse resulto primero el problema fiscal del país, la reforma de pensiones hubiera tenía un enfoque diferente, aunque eso supusiera implementar cambios en el diseño original del sistema, pero sin desnaturalizarlo tanto.

Sólo para poner un ejemplo, el adelanto de saldos parecería tener una finalidad funcional, más que responder a una eventualidad concreta que afecte un hito de la vida del trabajador al retirarse del mercado laboral; de hecho, es una paradoja desde el punto de vista de las decisiones intertemporales de consumo, tomando de base la teoría del ingreso permanente.
Daría la impresión que esto se incluyó en la reforma para desviar la atención de la reducción en el monto de las pensiones y del traslado de obligaciones de la Hacienda Pública a la Hacienda Privada de los trabajadores afiliados al SAP.

Palabras clave: Ahorro Complementario, Anticipo de Saldo, Beneficio de Longevidad, Beneficio Permanente, Beneficio Temporal, Capitales Complementarios, Cotizaciones y Aportes, Cuenta de Garantía Solidaria, Devoluciones de Saldo, Devoluciones de Saldo por Enfermedades Graves, Multifondos, Obligaciones Previsionales, Población Optada, Reforma a la Ley del Sistema de Aborro para Pensiones, Renta Programada.

\section{Introducción}

Antes de analizar los aspectos más importantes de la reforma al Sistema de Protección Social regulado a través de la Ley del SAP, es necesario señalar que los sistemas de Seguridad Social nacen durante la organización de los Estados modernos, cuando los Gobernantes tomaron conciencia de la necesidad de garantizar a la población, redes de protección con enfoque de derechos para enfrentar diversos estados de necesidad causados por contingencias sociales como la invalidez, la vejez y el fallecimiento prematuro de los trabajadores, antes de alcanzar la edad para jubilarse y que, por lo tanto, le sobrevivían familiares dependientes como hijos y cónyuges, por ejemplo.

Dichos sistemas de protección primitivos cubrían a una población reducida de la sociedad, ya que la informalidad era la caracte- 
rística predominante en los mercados laborales de ese entonces. ${ }^{1}$

Con el advenimiento de la revolución industrial y la proletarización de una buena parte de la clase trabajadora se promovieron esquemas de protección acordes con esa nueva realidad, los cuales se fueron extendiendo entre los países industrializados, cuyo financiamiento (Régimen Financiero) dependía de las aportaciones de trabajadores y empleadores, aunque su organización respondiera a Políticas Públicas de carácter social.

Antes de eso, la atención de contingencias sociales dependía de la asistencia de organizaciones religiosas o tenían un carácter bastante precario, donde ciertas comunidades o gremios establecían acuerdos implícitos de apoyo mutuo en caso de sufrir accidentes de trabajo; hay que recordar que en las condiciones sanitarias previas a la Revolución Industrial, un accidente de trabajo podría traducirse en una lesión incapacitante para el trabajador (amputaciones).

Es por esa razón que surgieron esquemas mutualistas de manera espontánea y con reglas diversas entre sí.

Ahora bien, los sistemas de Seguridad Social recientes se han organizado siguiendo los lineamientos de la Organización Internacional del Trabajo (OIT) y su Acuerdo 102 , inspirándose en el interés de proteger al trabajador a lo largo de toda su vida, desde los servicios de salud prenatales, la ayuda familiar, la educación, la seguridad social en el trabajo y su rehabilitación, en caso de accidentes, hasta el pago de rentas cuando los trabajadores abandonan el mercado laboral, etc.

La mayoría de sistemas de Seguridad Social comprenden un Régimen de Invalidez, Vejez y Muerte (IVM), con esquemas indemnizatorios para los trabajadores en caso de presentarse contingencias determinadas, consignadas explícitamente en las leyes de previsión social correspondientes.

Para gozar de protección social los trabajadores deben afiliarse a un régimen en particular y contribuir a su financiamiento con aportaciones monetarias a lo largo de su vida laboral ${ }^{2}$, hasta alcanzar cierta edad que, convencionalmente, la sociedad considera propicia para la jubilación. De cumplirse una serie de condiciones para acreditar derechos dentro de los regímenes previsionales, el trabajador recibe una Pensión de Vejez, a manera de fuente sustitutiva del salario.

La relación que existe entre el monto de la pensión recibida y los salarios previos reco-

Esto sigue caracterizando al mercado laboral salvadoreño.

La gran mayoría de regímenes previsionales son de carácter contributivo y las aportaciones efectuadas por sus partícipes 0 afiliados, según sea el caso, se enteran a entidades encargadas de administrar este tipo de servicios; las aportaciones frecuentemente son compartidas entre trabajadores y patronos y, la frecuencia de pago es mensual, sirviendo de base para el cálculo de la aportación, el salario devengado por el trabajador. El valor monetario de la aportación resulta, por lo tanto, de multiplicar la tasa de cotización acordada dentro del régimen previsional correspondiente y los ingresos percibidos por los trabajadores, a lo cual se le denomina Ingreso Base de Cotización (IBC), en el caso de El Salvador. 
nocidos a los trabajadores, antes de jubilarse, se denomina tasa de reemplazo y su cuantía puede incidir significativamente sobre la calidad de vida de los pensionados.

En la reforma que analizaremos en esta oportunidad, el legislador está revolucionando, prácticamente, la doctrina de Seguridad Social al crear un tipo de contingencia no prevista en dicho ámbito de estudio; nos estamos refiriendo aquí a la figura de la longevidad, que es una condición asociada con la duración de la vida de todas las personas y que, usualmente, se relaciona con la ancianidad, pero que es un aspecto intrínseco a la vida en sí.

En la reforma, por razones prácticas, más que doctrinarias o técnicas, se ha fijado como límite máximo de duración de una pensión de vejez, la edad de los 80 años; no obstante que la esperanza de vida al nacer en nuestro país, según datos oficiales del Ministerio de Economía publicados por la Dirección General de Estadísticas y Censos, es de 73 años.

Naturalmente que cuando se habla de vejez se nos viene a la mente el cambio demográfico ocurrido en el último siglo, dado que la longevidad actual supera claramente la registrada en el pasado.

Incluso, en algunos sistemas previsionales, como el español por ejemplo, se han introducido mecanismos de ajuste automático al monto de las pensiones ante el incremento de la longevidad de la población. ${ }^{3}$
En otros casos se habla de seguros de longevidad cuando las personas jubiladas agotan los ahorros que tenían para su retiro y, ante este evento, se utilizan productos financieros relacionados con la sobrevida de las personas, respecto a las tablas de mortalidad vigentes; particularmente cuando dichos cambios son de carácter estructural, es decir, que no corresponden a casos aislados que, dentro de la ley de los grandes números, ya están considerados en las tablas de mortalidad.

Dicho lo anterior, para analizar la reforma aprobada el 28 de septiembre del 2017, mediante la cual se cambió drásticamente la situación jurídica de los afiliados al Sistema de Ahorro para Pensiones, es necesario examinar cada uno de los elementos esenciales para el funcionamiento de un régimen previsional, como sería el procedimiento de incorporación del trabajador al régimen, la contribución a su régimen financiero, las reglas para acreditar derechos, los derechos reconocidos en sí, la norma para su ejercicio y la forma de pago de las prestaciones.

A fin de evaluar, en un contexto adecuado, la reforma implementada a partir del 28 de septiembre, es necesario mencionar que la población afiliada al 31 de diciembre del año 2013, según datos oficiales del Ministerio de Hacienda, ascendía a 1,675,576, correspondiendo el $89.6 \%$ a afiliados al SAP y

Cuando la longevidad de la población aumenta, el valor de las pensiones disminuye, a fin de preservar el equilibrio actuarial y financiero del sistema previsional. 
el restante 10.4\%, al Sistema de Pensiones Públicos (SPP).

En el caso de los afiliados al SAP, el 91.6\% eran personas obligadas a incorporarse al referido régimen ${ }^{4}$; mientras que el restante $8.4 \%$ caía en la categoría de optados; en contraposición con lo anterior, el 9.5\% de los afiliados al SPP formaban parte de la po- blación obligada a permanecer en el referido esquema de previsión social ${ }^{5}$ y, el $90.5 \%$ restante eran optados.

Dentro de esa población total, habían 160,686 pensionados entre ambos regímenes, $62.5 \%$ pertenecían al Sistema Público, y el 37.5\% restante, al SAP, tal como se aprecia en la siguiente ilustración:

\section{Ilustración 1: Afiliados al sistema de ahorro para pensiones - Diciembre 2013}

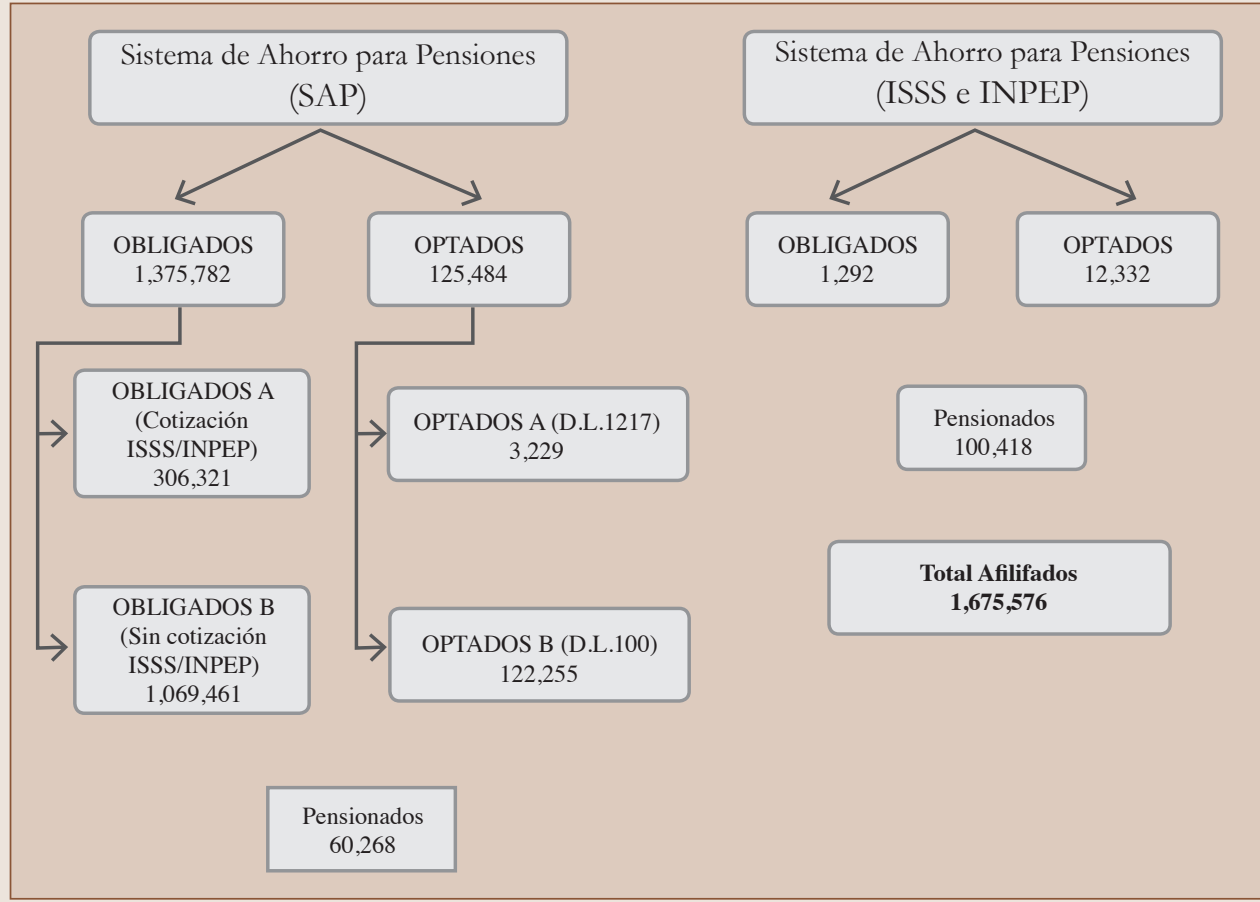

Fuente: Ministerio de Hacienda

$4 \quad$ Personas que al implementarse la Ley del SAP (abril de 1998) tenían menos de 36 años de edad.

5 Hombres mayores de 55 años de edad y mujeres, mayores de 50 años de edad. 
Cabe destacar aquí que, como lo indicaba el Ministerio de Hacienda, al 31 de diciembre del 2013, habían 125,484 optados en el SAP agrupados, por conveniencia analítica, en optados " $\mathrm{A}$ ", que eran personas que reunían los requisitos de tiempo y edad para gozar de beneficios bajo el Decreto Legislativo 1217 (Capital Complementario) y otros, identificados como optados "B", que recibirían sus prestaciones bajo el Decreto Legislativo 100 (Renta Vitalicia Pública).

Esto se ve más claramente en la siguiente ilustración elaborada por el Ministerio de Hacienda.

Ilustración 2: Afiliados al sistema de ahorro para pensiones, según su condición de activo 0 pensionado - Diciembre 2013

\begin{tabular}{|c|c|c|c|c|}
\hline SISTEMA & ACTIVOS & PENSIONADOS & TOTAL & $\%$ \\
\hline \multicolumn{5}{|c|}{ SAP } \\
\hline Obligados & 1375,782 & 21,769 & 1397,551 & 83.4 \\
\hline Optados A (D.L. 1217) & 3,229 & 22,642 & 25,871 & 1.5 \\
\hline Optados B (D.L. 100) & 122,255 & 15,857 & 138,112 & 8.2 \\
\hline Total SAP & 1501,266 & 60,268 & 1561,534 & 93.2 \\
\hline \multicolumn{5}{|c|}{ SPP } \\
\hline Optados & 12,332 & & 12,332 & 0.7 \\
\hline Obligados & 1,292 & 100,418 & 101,710 & 6.1 \\
\hline Total SPP & 13,624 & 100,418 & 114,042 & 6.8 \\
\hline Total General & 1514,890 & 160,686 & 1675,576 & 13.6 \\
\hline
\end{tabular}

Fuente: Ministerio de Hacienda

El 9.7\% de la población del SAP correspondía al segmento de optados; mientras que otro $0.7 \%$, del SPP, también pertenecían a dicho grupo. En otras palabras, de la referida población, el 10.4\% estaban comprendi- dos dentro de esa franja etaria cuando entró en vigencia la Ley del SAP, en abril de 1998.

Producto de la referida reforma de 1998, según información proporcionada por el 
Ministerio de Hacienda, el costo de transición entre ambos sistemas (de Reparto, a Capitalización Individual), expresado a Valor Actual, ascendía a $\$ 10,007.5$ millones; mientras que producto de las reformas subsiguientes, del año 2003 y 2006, respectivamente, se adicionaron otros $\$ 14,077.7$ millones a esa suma. Esto último por la discrepancia existente entre los beneficios ofrecidos en el régimen anterior y los obtenidos por la población optada que se traspasó al SAP.

El efecto comparación generado entre personas que, en igualdad de condiciones laborales y salariales, obtenían beneficios distintos por pertenecer al SPP o al SAP, ocasionó que se promovieran reformas que equipararan el pago de prestaciones entre la población optada, indistintamente si continuaban en el régimen público o se traspasaron al SAP; esto se dio a través del DL 1217 en el año 2003 y, con la emisión de Certificados de Traspasos Complementarios (CTC).

Posteriormente, ante la incapacidad financiera del Gobierno para cumplir con sus obligaciones previsionales y las dificultades que enfrentaba para financiar los costos de transición, mediante la contratación de deuda soberana, se adoptó el Fondo de Obligaciones Previsionales (FOP) en el año 2006, reemplazándose la forma de extinción de las obligaciones de equiparación de pensiones mediante un solo desembolso, por otra de extinción de éstas bajo un formato de tracto sucesivo (Rentas Vitalicias).
La implementación de reformas improvisadas derivó, entonces, en la reforma del 28 de septiembre del 2017.

Aunque para ser objetivos, es necesario señalar que el origen de los problemas fiscales que se pretendían aliviar con la reforma, no obedecían al sistema de pensiones implementado en el año de 1998 y que con dicha reforma sólo se habría mitigado la presión fiscal, trasladándole a los afiliados más jóvenes del SAP, casi el 50\% de los costos de transición aquí señalada, es decir, $\$ 12,633$ millones, mediante la figura de una Cuenta de Garantía Solidaria. ${ }^{6}$

Lo anterior, aunado a una reducción de obligaciones, a Valor Actual, de los compromisos estatales con la población optada, a quienes se les redujo el Valor Presente de sus derechos.

Observando la ilustración anterior, se aprecia que la reforma respondió, básicamente, a la presión de financiar la transición entre un Sistema de Reparto, a uno de Capitalización Individual, estructurada en la Ley del Sistema de Ahorro para Pensiones, del año de 1996.

6 Es importante señalar que la percepción de las calificadoras internacionales acerca del riesgo país no cambió a consecuencia de la reforma de pensiones, ya que las dificultades fiscales son principalmente de flujos y no de stock; sin embargo, el nivel de deuda soberana se redujo con esta medida; esto es parecido al Plan Brady de la década de los 80, destinado a reducir la deuda externa latinoamericana; se hizo, entonces, una restructuración de la deuda pública mediante la condonación de principal y reducciones de tasas. En el caso salvadoreño, se dio una reducción del principal adeudado a los pensionados actuales y futuros. 
La reforma más reciente a la Ley del SAP, al igual que la implementada en el año 2003, persigue equiparar, en parte, las pensiones entre regímenes para la población de optados, pero reduciéndole los beneficios a los optados del SAP.

llustración 3: Déficit actuarial del sistema previsional - diciembre 2013

\begin{tabular}{|l|r|c|}
\hline \multicolumn{1}{|c|}{ CONCEPTO } & \multicolumn{1}{c|}{ MONTO } & PORCENTAJE \\
\hline TOTAL SAP & $\mathbf{\$ 1 6 , 2 7 1 . 7}$ & $\mathbf{6 7 . 5 6 \%}$ \\
\hline Certificados de Traspaso (CT) & $\$ 2,194.1$ & $9.11 \%$ \\
\hline Certificados de Traspaso Complementario (CTC) & $\$ 29.2$ & $0.12 \%$ \\
\hline Beneficios Optados B & $\$ 7,702.3$ & $31.98 \%$ \\
\hline Pensión mínima y agotamiento de CIAP & $\$ 6,346.2$ & $26.35 \%$ \\
\hline TOTAL SPP & $\mathbf{\$ 7 , 8 1 3 . 5}$ & $\mathbf{3 2 . 4 4 \%}$ \\
\hline Beneficios & $\$ 7,645.6$ & $31.74 \%$ \\
\hline Gastos Admininistrativos & $\$ 167.9$ & $0.70 \%$ \\
\hline TOTAL SISTEMA & $\mathbf{\$ 2 4 , 0 8 5 . 2}$ & $\mathbf{1 0 0 . 0 0 \%}$ \\
\hline
\end{tabular}

Fuente: Ministerio de Hacienda

\section{Afiliación}

En cuanto a la regla de afiliación, ésta no cambió con la reforma; continúa siendo obligatoria para los trabajadores bajo relación de dependencia laboral y su incorporación debe realizarse al inicio de su vida laboral, en la AFP de su elección.

Se le asigna un número de registro en la AFP a la que se ha afiliado, el cual sirve de código para reportar sus cotizaciones y acreditar las aportaciones a su Cuenta Individual. ${ }^{7}$

En dicho proceso de afiliación interviene todavía la Superintendencia del Sistema Finan- ciero, quien maneja una base centralizada de afiliados al Sistema de Ahorro para Pensiones, encargándose de verificar que no existan duplicidades de registros para un mismo trabajador, previniéndose así, una posible dispersión de aportes en diferentes cuentas que dificultarían la labor de otorgamiento de prestaciones, cuando el trabajador desee ejercer su derecho a pensionarse.

De igual manera, si se efectúa un cambio entre una AFP y otra, el trabajador debe

7 Número Único Previsional (NUP). 
informarlo a su empleador, para enviar correctamente las cotizaciones a la AFP de destino del afiliado.

Cuando esto sucede (Traspaso del trabajador entre AFP) el saldo acumulado en una de ellas debe enviarse (Compensación de Traspasos) a la AFP de destino, para que ésta continúe invirtiendo dichos recursos hasta alcanzar los requisitos para pensionarse; en principio, este cambio puede realizarse después de haber efectuado 12 cotizaciones en una misma AFP; no obs- tante, la decisión de traspasarse entre administradoras debería valorarse responsablemente, ya que, a pesar que los sistemas de registros son confiables, suelen observarse errores en algunos datos de los afiliados cuando cambian de administradora.

\section{Cotización}

El porcentaje de cotización cambió del 13\% al 15\% y su distribución experimentará algunas modificaciones a lo largo del tiempo, tal como se muestra en las ilustraciones 4 y 5 :

\section{llustración 4: Tasas de cotización}

\begin{tabular}{crrrrrr}
\hline Años & Cotización & Aporte & Total CIAP & CGS & AFP & TOTAL \\
\hline 2017 & $7.25 \%$ & $0.75 \%$ & $8.0 \%$ & $5.0 \%$ & $2.0 \%$ & $15.0 \%$ \\
\hline 2018 & $7.25 \%$ & $0.75 \%$ & $8.0 \%$ & $5.0 \%$ & $2.0 \%$ & $15.0 \%$ \\
\hline 2019 & $7.25 \%$ & $0.80 \%$ & $8.1 \%$ & $5.0 \%$ & $2.0 \%$ & $15.0 \%$ \\
\hline$[2020,2027]$ & $7.25 \%$ & $0.85 \%$ & $8.1 \%$ & $5.0 \%$ & $1.9 \%$ & $15.0 \%$ \\
\hline$[2028,2037]$ & $7.25 \%$ & $1.35 \%$ & $8.6 \%$ & $4.5 \%$ & $1.9 \%$ & $15.0 \%$ \\
\hline$[2038,2043]$ & $7.25 \%$ & $1.85 \%$ & $9.1 \%$ & $4.0 \%$ & $1.9 \%$ & $15.0 \%$ \\
\hline$[2044,2049]$ & $7.25 \%$ & $2.85 \%$ & $10.1 \%$ & $3.0 \%$ & $1.9 \%$ & $15.0 \%$ \\
\hline$[2050, \infty]$ & $7.25 \%$ & $3.85 \%$ & $11.1 \%$ & $2.0 \%$ & $1.9 \%$ & $15.0 \%$ \\
\hline
\end{tabular}

Fuente: Elaboración propia

Lo novedoso de esta reforma consiste en la creación de una Cuenta de Garantía Solidaria que será constituida con los aportes de la población cotizante y de los pensionados del grupo de optados, estos últimos cotizarán a dicha cuenta entre el 3\% y el
$10 \%$ de su pensión, en función del monto de las mismas.

Dicha aportación estará a cargo de los empleadores y pasará, del 5\%, en el año 2017, al 2\%, del año 2050, en adelante. Además, 
de la cotización efectuada, el porcentaje destinado a la administración bajaría de $2.2 \%$, antes de la reforma, hasta el 1.9\%; pero esto sucederá después del año $2020{ }^{8}$

En este mismo sentido la cotización destinada a la Cuenta Individual se integrará en algunos de los fondos de inversión que podrán administrar las AFP, dependiendo de la edad de los afiliados. Mediante esta reforma se habilitan, por lo tanto, los multifondos; desde los denominados de "Crecimiento", pasando por los "Moderados" y, "Conservadores", hasta llegar a un fondo "Especial de Retiro". La diferencia entre dichos fon- dos corresponde al porcentaje que pueden invertir en instrumentos de renta variable; a pesar de la escasa diversificación del mercado de capitales del país.

A continuación se presenta cómo se distribuirá el 15\% de la cotización, a lo largo del tiempo, observándose que el porcentaje bruto para la administración del fondo (para la AFP) no cambiará significativamente; mientras que el porcentaje destinado a la Cuenta de Garantía Solidaria irá disminuyendo de manera gradual y, en sentido inverso al incremento gradual de la Cuenta Individual, claro está.

\section{Ilustración 5: Tasa de cotización al SAP}

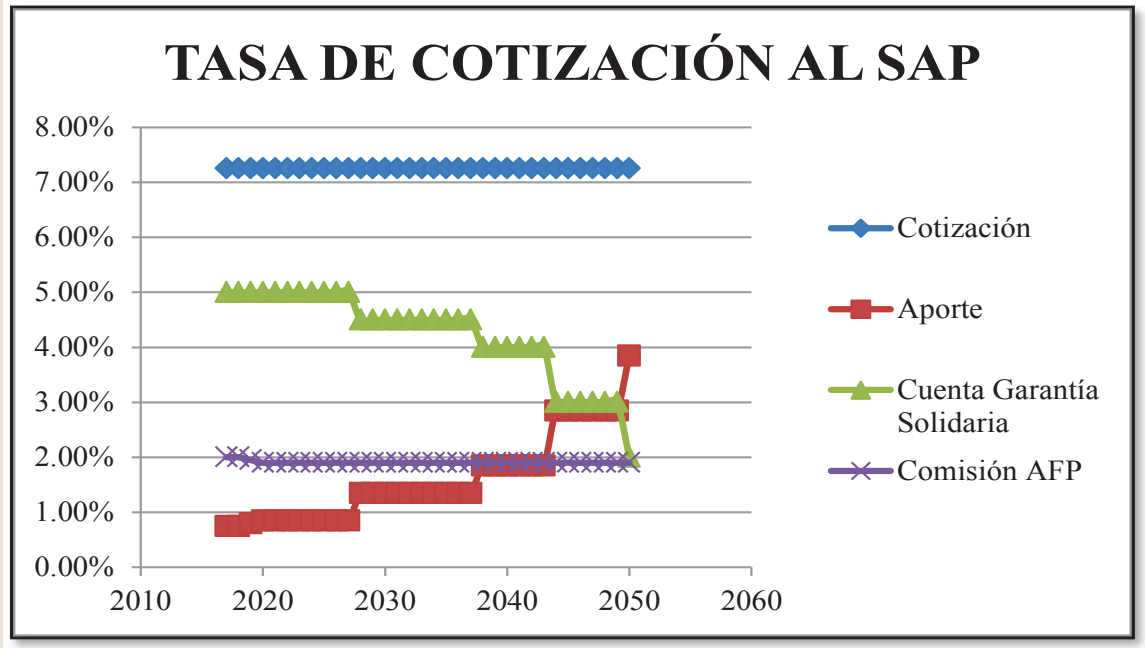

Fuente: Elaboración propia

8 Sin embargo, con el cambio de método de cálculo de las pensiones y prestaciones a los beneficiarios, la comisión por administración, neta de seguro, aumentará. 
A partir de la ilustración anterior se evidencia que, del 10.8\% destinado antes de la reforma, a la Cuenta Individual, se bajará al 8\% en los primeros años, afectando el ritmo de acumulación de ahorros para el retiro de los afiliados, especialmente de aquellos próximos a pensionarse; esta disminución se comenzará a corregir a partir del año 2044, es decir, 27 años después de la reforma.

Según el planteamiento del legislador, dicho efecto negativo se compensaría con el aumento en los rendimientos de los Fondos de Pensiones, lo cual es discutible, dado que la disminución de la base de crecimiento afectaría a los afiliados más jóvenes (menores de 35 años) que requerirían de una di- ferencia de rendimientos entre el Fondo de "Crecimiento" y el Fondo "Moderado", de unos 500 puntos básicos, aproximadamente, para compensar la acumulación de aportes en la CIAP.

Haciendo un ejercicio simple, para un salario de $\$ 750$ y una persona hipotética que en el año 2017 tuviera 22 años, con una densidad de cotización de $65.79 \%$ y un crecimiento salarial de 5\% cada 5 años; con las nuevas tasas de cotización, se requeriría de un rendimiento de $9.84 \%$ anual para obtener el mismo saldo acumulado por un afiliado que obtuviera $5 \%$ de rendimiento, pero que destinara $10.8 \%$ de su salario a su cuenta de ahorro para el retiro (CIAP), tal como se muestra en la siguiente ilustración: 
Ilustración 6: Acumulación en CIAP con cotización antes de la reforma y actual

TAE

Salario

Incremento quinquenal

Tasa de interés anual

Densidad de cotización

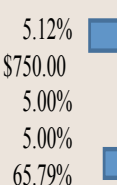

$65.79 \%$
$5.12 \%$

$\$ 750.00$

$5.00 \%$

$5.00 \%$

$65.79 \%$

\begin{tabular}{|c|c|c|c|c|c|c|}
\hline Edad & Años & Salario & $\mathrm{IBC}$ & Tasa Cotiz. & Anual & VF \\
\hline 22 & 2017 & $\$ 750.00$ & $\$ 493.43$ & $8.00 \%$ & $\$ 495.65$ & $\$ 495.65$ \\
\hline 23 & 2018 & $\$ 750.00$ & $\$ 493.43$ & $8.00 \%$ & $\$ 495.65$ & $\$ 1,042.34$ \\
\hline 24 & 2019 & $\$ 750.00$ & $\$ 493.43$ & $8.05 \%$ & $\$ 498.75$ & $\$ 1,648.42$ \\
\hline 25 & 2020 & $\$ 750.00$ & $\$ 493.43$ & $8.10 \%$ & $\$ 501.84$ & $\$ 2,320.02$ \\
\hline 26 & 2021 & $\$ 750.00$ & $\$ 493.43$ & $8.10 \%$ & $\$ 501.84$ & $\$ 3,060.77$ \\
\hline 27 & 2022 & $\$ 787.50$ & $\$ 518.10$ & $8.10 \%$ & $\$ 526.94$ & $\$ 3,902.89$ \\
\hline 28 & 2023 & $\$ 787.50$ & $\$ 518.10$ & $8.10 \%$ & $\$ 526.94$ & $\$ 4,831.73$ \\
\hline 29 & 2024 & $\$ 787.50$ & $\$ 518.10$ & $8.10 \%$ & $\$ 526.94$ & $\$ 5,856.23$ \\
\hline 30 & 2025 & $\$ 787.50$ & $\$ 518.10$ & $8.10 \%$ & $\$ 526.94$ & $\$ 6,986.22$ \\
\hline 31 & 2026 & $\$ 787.50$ & $\$ 518.10$ & $8.10 \%$ & $\$ 526.94$ & $\$ 8,232.57$ \\
\hline 32 & 2027 & $\$ 826.88$ & $\$ 544.00$ & $8.10 \%$ & $\$ 553.28$ & $\$ 9,633.61$ \\
\hline 33 & 2028 & $\$ 826.88$ & $\$ 544.00$ & $8.60 \%$ & $\$ 587.44$ & $\$ 11,213.08$ \\
\hline 34 & 2029 & $\$ 826.88$ & $\$ 544.00$ & $8.60 \%$ & $\$ 587.44$ & $\$ 12,955.20$ \\
\hline 35 & 2030 & $\$ 826.88$ & $\$ 544.00$ & $8.60 \%$ & $\$ 587.44$ & $\$ 14.876 .72$ \\
\hline 36 & 2031 & $\$ 826.88$ & $\$ 544.00$ & $8.60 \%$ & $\$ 574.46$ & $\$ 16,212,30$ \\
\hline 37 & 2032 & $\$ 868.22$ & $\$ 571.20$ & $8.60 \%$ & $\$ 603.18$ & $\$ 17,644.93$ \\
\hline 38 & 2033 & $\$ 868.22$ & $\$ 571.20$ & $8.60 \%$ & $\$ 603.18$ & $\$ 19,150.85$ \\
\hline 39 & 2034 & $\$ 868.22$ & $\$ 571.20$ & $8.60 \%$ & $\$ 603.18$ & $\$ 20,733.83$ \\
\hline 40 & 2035 & $\$ 868.22$ & $\$ 571.20$ & $8.60 \%$ & $\$ 603.18$ & $\$ 22,397.79$ \\
\hline 41 & 2036 & $\$ 868.22$ & $\$ 571.20$ & $8.60 \%$ & $\$ 603.18$ & $\$ 24,146.88$ \\
\hline 42 & 2037 & $\$ 911.63$ & $\$ 599.76$ & $8.60 \%$ & $\$ 633.34$ & $\$ 26,015.61$ \\
\hline 43 & 2038 & $\$ 911.63$ & $\$ 599.76$ & $9.10 \%$ & $\$ 670.16$ & $\$ 28,016.78$ \\
\hline 44 & 2039 & $\$ 911.63$ & $\$ 599.76$ & $9.10 \%$ & $\$ 670.16$ & $\$ 30,120.33$ \\
\hline 45 & 2040 & $\$ 911.63$ & $\$ 599.76$ & $9.10 \%$ & $\$ 670.16$ & $\$ 32,331.50$ \\
\hline 46 & 2041 & $\$ 911.63$ & $\$ 599.76$ & $9.10 \%$ & $\$ 670.16$ & $\$ 34,655.80$ \\
\hline 47 & 2042 & $\$ 957.21$ & $\$ 629.75$ & $9.10 \%$ & $\$ 703.67$ & $\$ 37,132.52$ \\
\hline 48 & 2043 & $\$ 957.21$ & $\$ 629.75$ & $9.10 \%$ & $\$ 703.67$ & $\$ 39,735.96$ \\
\hline 49 & 2044 & $\$ 957.21$ & $\$ 629.75$ & $10.10 \%$ & $\$ 780.99$ & $\$ 42,549.92$ \\
\hline 50 & 2045 & $\$ 957.21$ & $\$ 629.75$ & $10.10 \%$ & $\$ 780.99$ & $\$ 45,507.85$ \\
\hline 51 & 2046 & $\$ 957.21$ & $\$ 629.75$ & $10.10 \%$ & $\$ 780.99$ & $\$ 48,617.11$ \\
\hline 52 & 2047 & $\$ 1,005.07$ & $\$ 661.24$ & $10.10 \%$ & $\$ 820.04$ & $\$ 51,924.50$ \\
\hline 53 & 2048 & $\$ 1,005.07$ & $\$ 661.24$ & $10.10 \%$ & $\$ 820.04$ & $\$ 55,401.09$ \\
\hline 54 & 2049 & $\$ 1,005.07$ & $\$ 661.24$ & $10.10 \%$ & $\$ 820.04$ & $\$ 59,055.56$ \\
\hline 55 & 2050 & $\$ 1,005.07$ & $\$ 661.24$ & $11.10 \%$ & $\$ 901.23$ & $\$ 62,978.19$ \\
\hline 56 & 2051 & $\$ 1,005.07$ & $\$ 661.24$ & $11.10 \%$ & $\$ 901.23$ & $\$ 67,101.51$ \\
\hline 57 & 2052 & $\$ 1,055.33$ & $\$ 694.30$ & $11.10 \%$ & $\$ 946.30$ & $\$ 71,480.84$ \\
\hline 58 & 2053 & $\$ 1,055.33$ & $\$ 694.30$ & $11.10 \%$ & $\$ 946.30$ & $\$ 76,084.24$ \\
\hline 59 & 2054 & $\$ 1,055.33$ & $\$ 694.30$ & $11.10 \%$ & $\$ 946.30$ & $\$ 80,923.15$ \\
\hline 60 & 2055 & $\$ 1,055.33$ & $\$ 694.30$ & $11.10 \%$ & $\$ 946.30$ & $\$ 86,009.62$ \\
\hline
\end{tabular}

\begin{tabular}{|c|c|r|c|c|}
\hline Salario & IBC & Tasa Cotiz. & Anual & VF \\
\hline$\$ 750.00$ & $\$ 493.43$ & $10.80 \%$ & $\$ 654.34$ & $\$ 654.34$ \\
\hline$\$ 750.00$ & $\$ 493.43$ & $10.80 \%$ & $\$ 654.34$ & $\$ 1,342.16$ \\
\hline$\$ 750.00$ & $\$ 493.43$ & $10.80 \%$ & $\$ 654.34$ & $\$ 2,065.16$ \\
\hline$\$ 750.00$ & $\$ 493.43$ & $10.80 \%$ & $\$ 654.34$ & $\$ 2,825.16$ \\
\hline$\$ 750.00$ & $\$ 493.43$ & $10.80 \%$ & $\$ 654.34$ & $\$ 3,624.04$ \\
\hline$\$ 787.50$ & $\$ 518.10$ & $10.80 \%$ & $\$ 687.06$ & $\$ 4,496.51$ \\
\hline$\$ 787.50$ & $\$ 518.10$ & $10.80 \%$ & $\$ 687.06$ & $\$ 5,413.61$ \\
\hline$\$ 787.50$ & $\$ 518.10$ & $10.80 \%$ & $\$ 687.06$ & $\$ 6,377.64$ \\
\hline$\$ 787.50$ & $\$ 518.10$ & $10.80 \%$ & $\$ 687.06$ & $\$ 7,390.99$ \\
\hline$\$ 787.50$ & $\$ 518.10$ & $10.80 \%$ & $\$ 687.06$ & $\$ 8,456.18$ \\
\hline$\$ 826.88$ & $\$ 544.00$ & $10.80 \%$ & $\$ 721.41$ & $\$ 9,610.22$ \\
\hline$\$ 826.88$ & $\$ 544.00$ & $10.80 \%$ & $\$ 721.41$ & $\$ 10,823.31$ \\
\hline$\$ 826.88$ & $\$ 544.00$ & $10.80 \%$ & $\$ 721.41$ & $\$ 12,098.46$ \\
\hline$\$ 826.88$ & $\$ 544.00$ & $10.80 \%$ & $\$ 721.41$ & $\$ 13,438.85$ \\
\hline$\$ 826.88$ & $\$ 544.00$ & $10.80 \%$ & $\$ 721.41$ & $\$ 14,847.81$ \\
\hline$\$ 868.22$ & $\$ 571.20$ & $10.80 \%$ & $\$ 757.48$ & $\$ 16,364.93$ \\
\hline$\$ 868.22$ & $\$ 571.20$ & $10.80 \%$ & $\$ 757.48$ & $\$ 17,959.67$ \\
\hline$\$ 868.22$ & $\$ 571.20$ & $10.80 \%$ & $\$ 757.48$ & $\$ 19,636.00$ \\
\hline$\$ 868.22$ & $\$ 571.20$ & $10.80 \%$ & $\$ 757.48$ & $\$ 21,398.10$ \\
\hline$\$ 868.22$ & $\$ 571.20$ & $10.80 \%$ & $\$ 757.48$ & $\$ 23,250.34$ \\
\hline$\$ 911.63$ & $\$ 599.76$ & $10.80 \%$ & $\$ 795.35$ & $\$ 25,235.23$ \\
\hline$\$ 911.63$ & $\$ 599.76$ & $10.80 \%$ & $\$ 795.35$ & $\$ 27,321.66$ \\
\hline$\$ 911.63$ & $\$ 599.76$ & $10.80 \%$ & $\$ 795.35$ & $\$ 29,514.85$ \\
\hline$\$ 911.63$ & $\$ 599.76$ & $10.80 \%$ & $\$ 795.35$ & $\$ 31,820.23$ \\
\hline$\$ 911.63$ & $\$ 599.76$ & $10.80 \%$ & $\$ 795.35$ & $\$ 34,243.57$ \\
\hline$\$ 957.21$ & $\$ 629.75$ & $10.80 \%$ & $\$ 835.12$ & $\$ 36,830.66$ \\
\hline$\$ 957.21$ & $\$ 629.75$ & $10.80 \%$ & $\$ 835.12$ & $\$ 39,550.11$ \\
\hline$\$ 957.21$ & $\$ 629.75$ & $10.80 \%$ & $\$ 835.12$ & $\$ 42,408.68$ \\
\hline$\$ 957.21$ & $\$ 629.75$ & $10.80 \%$ & $\$ 835.12$ & $\$ 45,413.51$ \\
\hline$\$ 957.21$ & $\$ 629.75$ & $10.80 \%$ & $\$ 835.12$ & $\$ 48,572.08$ \\
\hline$\$ 1,005.07$ & $\$ 661.24$ & $10.80 \%$ & $\$ 876.88$ & $\$ 51,933.99$ \\
\hline$\$ 1,005.07$ & $\$ 661.24$ & $10.80 \%$ & $\$ 876.88$ & $\$ 55,467.91$ \\
\hline$\$ 1,005.07$ & $\$ 661.24$ & $10.80 \%$ & $\$ 876.88$ & $\$ 59,182.63$ \\
\hline$\$ 1,005.07$ & $\$ 661.24$ & $10.80 \%$ & $\$ 876.88$ & $\$ 63,087.40$ \\
\hline$\$ 1,005.07$ & $\$ 661.24$ & $10.80 \%$ & $\$ 876.88$ & $\$ 67,191.95$ \\
\hline$\$ 1,055.33$ & $\$ 694.30$ & $10.80 \%$ & $\$ 920.72$ & $\$ 71,550.34$ \\
\hline$\$ 1,055.33$ & $\$ 694.30$ & $10.80 \%$ & $\$ 920.72$ & $\$ 76,131.71$ \\
\hline$\$ 1,055.33$ & $\$ 694.30$ & $10.80 \%$ & $\$ 920.72$ & $\$ 80,947.48$ \\
\hline$\$ 1,055.33$ & $\$ 694.30$ & $10.80 \%$ & $\$ 920.72$ & $\$ 86,009.62$ \\
\hline & & & & \\
\hline
\end{tabular}

Fuente: Elaboración propia 
En el ejercicio anterior se considera la situación de un joven que inicia su vida laboral a los 22 años y que al cumplir los 60, ya ha acumulado 25 años de cotización (densidad de cotización $=65.79 \%$ ) y que, según la reforma, podría cotizar al Fondo de Pensiones de "Crecimiento", hasta los 35 años de edad; en comparación con una persona, con la misma edad, que hubiera cotizado bajo el formato anterior $(10.8 \%$ a la CIAP) en un único fondo equivalente al moderado.

En tales condiciones, ese trabajador hubiera acumulado $\$ 86,009.62$ en su cuenta; con las nuevas tasas de cotización a la CIAP, para acumular la misma cantidad, el afiliado tendría que obtener rendimientos anuales de $9.84 \%$, entre los 22 años y los 35 años de edad, cuando invertía en el fondo de crecimiento.

A continuación se muestran las condiciones a que se refiere la Ley en materia de multifondos, clasificándolos en 4; entre ellos iría transitando el trabajador a lo largo de la vida, según el rango de edad que se señala en la tabla.

\section{Ilustración 7: Multifondos}

\begin{tabular}{lcc}
\hline \multicolumn{1}{r}{ Fondo } & Renta Variable & Rango de edad \\
Crecimiento & {$[30 \%, 45 \%]$} & $\mathrm{X}<36$ años \\
\hline Moderado & {$[20 \%, 30 \%]$} & $36<\mathrm{X}<50$ años $(\mathrm{M})$ \\
& & $36<\mathrm{X}<55$ años $(\mathrm{H})$ \\
\hline Conservador & {$[0 \%, 20 \%]$} & El resto \\
\hline Especial de Retiro & $0 \%$ & Pensionados \\
\hline
\end{tabular}

Fuente: Elaboración propia

Los multifondos se caracterizan por invertir una mayor cantidad de dinero en Renta Variable, cuando el afiliado es joven y puede recuperarse de fluctuaciones importantes en los rendimientos del mercado de capitales; luego, el nivel de exposición al riesgo (Instrumentos de Renta Variable) tiende a disminuir, hasta casi desaparecer cuando el trabajador ya está jubilado. En tales circunstancias, el afiliado no estaría interesado en especular con el saldo de su cuenta y preferiría rendimientos bajos, pero seguros.

Con el valor acumulado en la cuenta que aparece anteriormente, la pensión del trabajador sería de $\$ 461.72$, considerando una 
tasa de descuento del 5\% y una renta cierta de 20 años. De no lograrse el rendimiento de $9.84 \%$ en los primeros 13 años de cotización (Fondo de Crecimiento), su pensión podría reducir hasta $\$ 373.51$, en caso de obtenerse un rendimiento del 5\% anual, en ese mismo período, tal como se presenta en la siguiente ilustración:

\section{Ilustración 8: Monto de pensión con diferentes rendimientos en la CIAP, durante la fase de inversión en el fondo de crecimiento}

\begin{tabular}{rr}
\hline Pensión & $\$ 461,72$ \\
$5,00 \%$ & $\$ 373,51$ \\
$5,50 \%$ & $\$ 380,81$ \\
$6,00 \%$ & $\$ 388,48$ \\
$6,50 \%$ & $\$ 396,53$ \\
$7,00 \%$ & $\$ 404,97$ \\
$7,50 \%$ & $\$ 413,84$ \\
$8,00 \%$ & $\$ 423,16$ \\
$8,50 \%$ & $\$ 432,94$ \\
$9,00 \%$ & $\$ 443,22$ \\
$9,50 \%$ & $\$ 454,03$ \\
$10,00 \%$ & $\$ 465,38$ \\
\hline
\end{tabular}

Fuente: Elaboración propia

La tabla anterior muestra diferentes rendimientos para los primeros 13 años del proceso de acumulación, con las nuevas tasas de cotización, en comparación con las vigentes antes de la reforma (10.8\%); de no lograrse los rendimientos antes mencionados $(9.84 \%)$, el monto de la pensión sería inferior a la obtenida antes de la reforma. En otras palabras, se obtendría menos pensión, con una cotización más alta.

De hecho la nueva forma de calcular la pensión conduce a tasas de reemplazo inferiores, ya que la expectativa de vida de la persona al pensionarse (60 años los hombres y 55 años las mujeres) es menor a 20 años, como se ha dispuesto en la normativa vigente'. De ahí que, al distribuirse dicho saldo entre un número de años mayor, es lógico esperar que el coeficiente resultante (monto de pensión) sea más bajo.

9 En las tablas que se usaban antes para calcular las pensiones de vejez se tenía una expectativa de vida de 11.7 años al alcanzar los 60 años (hombres). 


\section{Recaudación}

En cuanto a la recaudación se refiere, el cambio más relevante consiste en la forma de gestionar el cobro administrativo y judicial de la mora patronal relativa al pago de cotizaciones, donde se han agregado aspectos interesantes que pueden facilitar la recuperación de aportes y cotizaciones a favor de los trabajadores.

Aunque el régimen de infracciones y sanciones no ha cambiado y continúa siendo un delito la apropiación indebida de las cotizaciones de los trabajadores, lo que ha cambiado es la forma de tramitar los cobros judiciales por parte de las AFP, en representación de sus afiliados. No hay que olvidar que, a diferencia de un Sistema de Reparto administrado por una institución pública, como el ISSS, las cotizaciones no pagadas por los empleadores, al de Capitalización Individual, se adeudan a los trabajadores, no a la administradoras de esos fondos (AFP).

Las instancias competentes para conocer este tipo de reclamaciones continúan siendo los Tribunales de lo Mercantil; aunque el documento base de la acción ya no requiere del reconocimiento de la deuda por parte de los empleadores, en contraposición con lo que sucedía antes de la reforma.

Esta modificación debería facilitar el cobro judicial, especialmente porque el cobro administrativo ya no constituiría una condición sine qua non para incorporar acciones en contra del empleador, en sede judicial.
En el pasado, el reconocimiento de la deuda por parte del empleador constituía un escoyo para el cobro, impidiendo incluso la suscripción de acuerdos de pago en representación de los afiliados; la forma en que se procedía, anteriormente, con empleadores morosos era facilitarles acuerdos unilaterales de pago, que firmaban para poder participar en licitaciones de suministros de bienes y concurso de provisión de servicios con instituciones del Estado.

Sobre esto último cabe recordar que para participar en tales procesos, los participantes deben presentar solvencias de pago de sus obligaciones previsionales, entre otra documentación, para esos efectos. Este era un recurso utilizado para presionar por el cumplimiento de obligaciones previsionales por parte de algunos empleadores morosos y que eran, a su vez, proveedores de entidades públicas.

Hoy se propone reportar el incumplimiento de pagos a la Central de Riesgos administrada por la Superintendencia del Sistema Financiero, lo cual podría cerrarle el acceso al crédito bancario a los empleadores que hayan incumplido este tipo de obligaciones.

De igual manera se está considerando la intervención del Ministerio de Trabajo como fedatario de la deuda previsional de los empleadores, sirviendo sus informes de prueba para iniciar acciones de cobro judicial.

En ese mismo sentido, se prevé una comunicación trimestral de parte de las AFP y Ministerio de Trabajo sobre el incumpli- 
miento de pago de los empleadores, a fin de inspeccionar determinados centros de trabajo y brindarle a las instituciones administradoras, las certificaciones necesarias para iniciar la cobranza judicial; estas últimas serán responsables siempre de la acción de cobro, pero ahora con el soporte de las referidas certificaciones.

$\mathrm{Al}$ tener un estimado razonable del monto adeudado por algún empleador, las AFP deberán registrar dicha obligación como una Cuenta por Cobrar y calcularle los intereses devengados, por su Fondo Conservador, como rentabilidad dejada de percibir.

También se prevé la colaboración con el Registro Nacional de Personas Naturales para la depuración de la información relacionada con la población afiliada.

\section{Cuenta de garantía solidaria}

La reforma contempla la creación de una Cuenta de Garantía Solidaria que será administrada por las AFP, pero que no pertenecerá a los afiliados, sino que tendrá el carácter de una cuenta común, tal como se acostumbra en un Sistema de Reparto.

Es mediante esta Cuenta Solidaria que se ha trasladado parte de las obligaciones previsionales, del Estado, a los afiliados al SAP, vía menor acumulación en sus cuentas individuales.

Esta Cuenta Solidaria se utilizará para los siguientes propósitos: a) Pago de pensiones de longevidad de los afiliados a los que se refiere el artículo 184, al agotarse el saldo de su Cuenta Individual;

b) Pago de pensiones de vejez en segunda etapa de los afiliados a los que se refiere el artículo 184-A;

c) Pago de un valor equivalente a los Certificados de Traspaso y Certificados de Traspaso Complementarios que les hubiera correspondido a los afiliados a los que se refieren los artículos 184 y 184-A, por las cotizaciones que realizaron a los Institutos Previsionales del Sistema de Pensiones Público;

d) Pago de Pensiones mínimas de vejez, invalidez y sobrevivencia a las que se refiere el Art. 147, 148 y 149;

e) Pensiones por sobrevivencia, para beneficiarios de afiliados causantes contemplados en las letras a), b) y f) de este inciso, de conformidad a las condiciones de otorgamiento y goce, aplicables a cada caso;

f) Pensiones de longevidad de los afiliados a los que se refiere el artículo 185 de esta Ley, luego de haber transcurrido el período en el que le correspondiere gozar de pensión por vejez según lo establece el artículo 131 de esta Ley;

g) Beneficios por longevidad de los afiliados a los que se refiere el artículo 126-B de esta Ley, luego de agotarse el saldo de su cuenta individual; y

h) Devoluciones de aportes a los afiliados que no cumplen los requisitos para acceder a ningún otro beneficio cubierto con recursos de la Cuenta de Garantía 
Solidaria, salvo el establecido en la letra c) anterior.

Según estimaciones realizadas por el actuario José Rodolfo Castillo, el Valor Presente de las obligaciones traspasadas a la Cuenta de Garantía Solidaria ascendería a unos \$12,633 millones, utilizando para el cálculo una tasa de descuento del 4\%; lo cual es razonable para este tipo de estimaciones.

Ilustración 9: Obligaciones traspasadas a la cuenta de garantía solidaria -En millones

\begin{tabular}{ccccc}
\hline $\begin{array}{c}\text { Tasa de } \\
\text { Descuento }\end{array}$ & $\begin{array}{c}\text { Certificados de } \\
\text { Traspaso }\end{array}$ & $\begin{array}{c}\text { Beneficios } \\
\text { previsionales } \\
\text { Optados B }\end{array}$ & $\begin{array}{c}\text { Beneficios } \\
\text { previsionales } \\
\text { Pensión Mínima }\end{array}$ & Total \\
\hline $0 \%$ & $\$ 2,912.7$ & $\$ 11,189.4$ & $\$ 85,736.9$ & $\$ 99,839.0$ \\
\hline $1 \%$ & $\$ 2,655.4$ & $\$ 9,332.6$ & $\$ 34,580.6$ & $\$ 46,568.6$ \\
\hline $2 \%$ & $\$ 2,429.2$ & $\$ 7,875.0$ & $\$ 16,003.4$ & $\$ 26,307.6$ \\
\hline $3 \%$ & $\$ 2,229.7$ & $\$ 6,717.5$ & $\$ 8,345.6$ & $\$ 17,292.8$ \\
\hline $4 \%$ & $\$ 2,053.1$ & $\$ 5,788.2$ & $\$ 4,791.7$ & $\$ 12,633.0$ \\
\hline $5 \%$ & $\$ 1,896.3$ & $\$ 5,034.3$ & $\$ 2,966.2$ & $\$ 9,896.8$ \\
\hline $6 \%$ & $\$ 1,756.5$ & $\$ 4,416.7$ & $\$ 1,948.1$ & $\$ 8,121.3$ \\
\hline
\end{tabular}

Fuente: José Rodolfo Castillo, Actuario.

En el cuadro anterior se ilustran los diferentes ítems estimados por el actuario, entre los cuales están los Certificados de Traspaso y Certificados de Traspaso Complementarios; así como el pago de beneficios para los optados "B", una vez agotados el saldo de su cuenta y, el Valor Presente de las pensiones mínimas.

Al revisar los datos publicados por el Ministerio de Hacienda, para el año 2013, que fijaba el Valor Presente de la deuda previsional en $\$ 24,085.2$ millones, se podría decir que el 52.5\% de las obligaciones del Estado habían sido traspasadas a la Cuenta de Garantía Solidaria. No obstante, debemos advertir que se desconoce la tasa de descuento utilizada por el Gobierno en el 2013 y que las dos cifras no corresponden al mismo año de análisis.

Además, como veremos más adelante otra parte importante de las obligaciones del Estado se extinguieron mediante la dilución de las obligaciones que tenía el Estado con la población de optados. 


\section{Multifondos}

Otro aspecto que sufrió cambios en la Ley del SAP, como resultado de la última reforma, está relacionado con las inversiones de los Fondos de Pensiones, que como ya se mencionó antes, abrió la posibilidad para que una AFP administrara varios portafolios de inversión; cuatro para ser precisos, diferenciándose entre sí por el porcentaje de instrumentos de renta variables que podrían adquirir.

El afiliado continúa teniendo una sola cuenta dentro del Fondo, pero en función de su edad participará dentro de una cartera más expuesta a fluctuaciones en sus rendimientos (riesgo), en relación con las otras.

La base teórica de esta propuesta, consiste en que los jóvenes pueden asumir más riesgo que los afiliados próximos a pensionarse, porque cuentan con más tiempo para recuperarse de algún descalabro financiero; por lo tanto, los trabajadores próximos a pensionarse y los jubilados, principalmente, deberían tener invertidos sus ahorros en instrumentos seguros, tal como se muestra a continuación.

Ilustración 10: Composición de los multifondos

\begin{tabular}{lcc}
\hline \multicolumn{1}{c}{ Tipo de Fondo } & Renta Variable & Renta Fija \\
\hline Crecimiento & $45 \%$ & $55 \%$ \\
\hline Moderado & $30 \%$ & $70 \%$ \\
\hline Conservador & $20 \%$ & $80 \%$ \\
\hline Especial de Retiro & & $100 \%$ \\
\hline
\end{tabular}

Fuente: Elaboración propia

En la ilustración anterior se muestra con color, el porcentaje de renta variable permitido en cada categoría de fondo; sin embargo, esto enfrenta un problema básico; el escaso desarrollo del mercado de capitales en el país, donde la mayor parte de transacciones registradas en Bolsa corresponden a instrumentos financieros de renta fija y, en buena medida, del mercado de dinero, no de capital. 
Del rendimiento futuro de estas inversiones dependerá el monto de las pensiones futuras de los afiliados al SAP.

$\mathrm{Al}$ recibirse las cotizaciones de los trabajadores, a través de las planillas de declaración y pago por parte de sus respectivos empleadores, las AFP las acreditarán en el "Fondo Conservador", mientras identifica a quién deben abonarle cada importe y dependiendo del fondo a que pertenezca, trasladará las cotizaciones donde correspondan. Eso mismo se aplicará a las Cuentas por Cobrar a empleadores morosos (se registrarán dichos compromisos en el Fondo Conservador), mientras se recuperan las cotizaciones adeudadas.

Por otro lado, la Cuenta de Garantía Solidaria se administrará en la cartera conservadora; aunque no se dice por qué en la norma.

Como ha sucedido en otros países donde se han implementado esquemas de multifondos, como herramienta para la capitalización del ahorro previsional de los trabajadores; cuando se hayan constituido los fondos en comento, los afiliados tendrán la opción de elegir entre ellos, siempre y cuando le queden más de 5 años para pensionarse; si dentro de 90 días no elige, la AFP deberá pasarlo a la categoría de inversión que le corresponda, según la norma; el resto deberá estar en el "Fondo Conservador" mientras alcanzan la edad para jubilarse, pasando luego al "Fondo Especial de Retiro".

Lo mismo sucederá cuando cumplan los 36 años; si dentro del año siguiente, no elige, se le pasará al "Fondo Conservador".
La legislación también contempla la inversión en mercados organizados en el extranjero y en instrumentos derivados para la cobertura de diversos tipos de riesgo, pero no para la especulación.

\section{Ahorro previsional voluntario}

Teniendo presente que bajo el esquema de Seguridad Social adoptado mediante la reforma de septiembre se reducirán los montos de las pensiones futuras y que la participación del Estado en el diseño e implementación de políticas sociales, en esta materia, tienden a desaparecer, dejándole a los trabajadores la responsabilidad exclusiva de ahorrar para su retiro, la reforma contempla el desarrollo de nuevas formas de ahorro complementario, similares a las existentes en otros países; a manera de ejemplo, el "401 K" de los Estados Unidos.

Debido a las restricciones de inversión que enfrentan las Administradoras de Fondos de Pensiones, resulta natural que estos programas sean gestionados por otras instituciones financieras, aunque siempre especializadas en la gestión del riesgo financiero y de longevidad, como serían las compañías de seguros que manejan planes de jubilación en otros países.

No obstante lo anterior, en la reforma se plantea la creación de nuevas instituciones dedicadas a estas actividades, aunque siempre bajo la tutela de la Superintendencia Sistema Financiero. 
A diferencia de los planes de jubilación existentes en otros países, los aportes destinados a la acumulación de recursos para el retiro se manejarían como Cuentas Individuales propiedad de los partícipes y no como planes ofrecidos como productos financieros, por compañías de seguros, como sucede en España, Estados Unidos o Suecia.

La ventaja de este planteamiento es que las cotizaciones destinadas a fondos de ahorro previsional voluntario gozarán de exenciones fiscales, hasta el 10\% de la renta imponible declarada por las personas en el ejercicio fiscal inmediato anterior.

Por otro lado, es importante mencionar que este tipo de ahorro es de libre disponibilidad, a diferencia del ahorro convencional para el retiro que, siendo propiedad de los ahorrantes, no se debería retirar, anticipadamente, por estar destinado al consumo futuro (pagos de rentas jubilatorias); aunque si dichos retiros se efectúan dentro de los primeros 5 años de su constitución, se considerarán ingresos gravables. Algo similar se estila en Costa Rica.

Además, como sucede en varios países nórdicos, se plantea aquí la figura de planes individuales y planes institucionales, que en Suecia se denominan planes profesionales, por ser promovidos o auspiciados por empresas o gremios que contratan este tipo de productos con entidades financieras.

Los portafolios de inversiones adquiridos con recursos de los cotizantes serán de su propiedad, aunque gestionados por institu- ciones autorizadas por la Superintendencia para tales menesteres.

Otra diferencia con los fondos gestionados por las AFP, respecto a las entidades de las que estamos hablando, es que las personas podrán realizar aportes a diferentes fondos.

Estos ahorros, por su naturaleza privada, formarán parte del haber sucesoral de las personas, para lo cual los afiliados deberán designar a sus beneficiarios, sin que una eventual sucesión de éstos resulte gravada por el Ministerio de Hacienda, en ningún sentido.

Al igual que las AFP, estas administradoras cobrarán una comisión por el servicio, a diferencia de las primas cobradas por las compañías de seguro que ofrecen planes de jubilación con beneficios garantizados, donde la ganancia de éstas forma parte del valor de las primas.

Claro está que este tipo de esquemas benefician a las personas con mayores ingresos de la sociedad, donde el porcentaje de rentas percibidas cuando se retiran del mercado laboral depende, mayoritariamente, del ahorro financiero acumulado voluntariamente; mientras que el peso relativo de los esquemas obligatorios, para dichas personas, puede ser poco significativo, especialmente, cuando existen varios pilares de seguridad social.

En relación con esto último, vale la pena mencionar que en muchos países desarrollados conviven esquemas multipilares; con una pensión universal básica, otra proveniente de cotizaciones obligatorias de be- 
neficio definido o contribución definida, según el caso, y, finalmente, con esquemas complementarios de ahorro voluntario.

En el caso de México, por ejemplo, los planes privados de pensiones son algo convencional, existiendo planes privados de contribución definida, de beneficio definido y otros de carácter mixto. Estos planes pueden estar registrados o no, en la Comisión Nacional del Sistema de Ahorro para el Retiro (CONSAR); sus patrocinadores son empresas y las contribuciones a dichos esquemas pueden provenir de éstas en su totalidad o contar con aportaciones también, de los trabajadores afiliados.

Dichos esquemas han venido migrando de beneficio definido donde las prestaciones se otorgan en función del salario y años de servicio del trabajador, recayendo en la empresa el riesgo financiero y de sobrevida de los pensionados, hacia otros planes de contribución definida asociados con el valor acumulado por cada trabajador; finalmente, los planes mixtos dependen del saldo acumulado, pero con una garantía de beneficio mínimo ofrecida por la empresa.

Hasta 1995 los planes de beneficios definido en México, representaban el 91.4\%; el 1.4\% eran planes de contribución definida y; el restante $7.2 \%$ eran mixtos. Para el 2014 esta estructura había cambiado; los planes de beneficio definido representaban el 29.4\%; los de contribución definida, el $18.8 \%$ y; el restante $51.8 \%$ eran mixtos. La tendencia es hacia planes mixtos con aportes de empleadores y trabajadores. Tan es así, que los operadores de estos planes facilitan la declaración de aportaciones, de los trabajadores, mediante pagos electrónicos.

\section{Adelanto de saldo}

Originalmente los sistemas de Seguridad Social inspirados en los Convenios de la OIT se expresaban en políticas focalizadas para cada hito de la vida de los trabajadores, proporcionando atenciones durante su gestación, ayuda familiar durante el desarrollo, servicios de educación previos a la incorporación al mercado laboral, programas de salud por riesgos profesionales y comunes, programas de vivienda social, planes de rehabilitación en caso de accidentes o enfermedades, la reeducación para el trabajo en caso de desempleo friccional, esquemas de cesantía en edad avanzada, formatos indemnizatorios (pensiones de invalidez, sobrevivencia y vejez) y servicios de sepelio.

En otras palabras, la visión de la OIT era apoyar al trabajador desde la cuna hasta la tumba, de ahí que, era inconcebible que los regímenes de pensiones tuvieran destinos distintos al pago de pensiones de vejez, invalidez o sobrevivencia.

Naturalmente que, algunas entidades gestoras públicas que administraban diversos regímenes, otorgaban préstamos para la educación de los hijos de los afiliados, para la compra de vivienda y necesidades personales de emergencia.

No obstante lo anterior, este tipo de prestaciones se financiaba con cargo a las reservas 
constituidas para el pago de pensiones futuras y los afiliados debían cancelar dichos préstamos mediante abonos mensuales; pero, en ningún momento se mezclaba las bases doctrinarias de cada régimen, en contraposición con lo observado en la reforma del 28 de septiembre.

Es más, cuando se promulgó la Ley del SAP en 1996, inspirada en la legislación chilena en esa misma materia, se tenía bastante claridad sobre el destino exclusivo de la cuenta para el pago de prestaciones jubilatorias.
Con la reforma de septiembre se abrió la posibilidad para que los afiliados puedan retirar, anticipadamente, hasta el $25 \%$ del saldo disponible en su cuenta, para otros propósitos, con el compromiso de reintegrarlo antes de acceder a la pensión de vejez.

De no cancelarse el saldo completo, el trabajador tendría que postergar la fecha para ejercitar su derecho a pensión de vejez, tal como se muestra en la siguiente ilustración:

\section{llustración 11: Postergación de pensión según porcentaje de impago del adelanto}

Porcentaje de reintegro

[0\%, 20\%[

[20\%, 40\%[

[40\%, 60\%[

$[60 \%, 80 \%[$

[80\%, 100\%[
Años de diferimiento de pensión

5 Años

4 Años

3 Años

2 Años

1 Años

Fuente: Decreto Legislativo 787

La Ley contempla que si un trabajador ha retirado fondos de su cuenta y adeuda, menos del 20\% de lo solicitado, es decir, si ha reintegrado más del $80 \%$ de lo retirado, deberá postergar el momento de pensionarse, un año completo; si adeuda entre $20 \%$ y $40 \%{ }^{10}$, dos años y, así sucesivamente hasta la postergación de 5 años.
En tal sentido, con dicha reforma se distorsiona la concepción doctrinaria de la pensión por vejez, la cual tendría que depender, exclusivamente, de la edad del trabajador.

10 En otras palabras, si ha reintegrado menos del $80 \%$ de lo solicitado como anticipo, pero más del $60 \%$. 
Este tipo de planteamiento tendría sentido para un plan de ahorro para pensiones complementario, como el de la sección anterior, tal como sucede en Costa Rica y en México; aunque en el caso de México el período de carencia es de 10 años y no de 5, como en Costa Rica.

Parecería ser que, esta disposición tiene como finalidad facilitar, de alguna manera, la aceptación de la reforma, apelando a la preferencia por liquidez de las personas y ofreciendo respuestas inmediatas a las necesidades que atraviesan los trabajadores antes de alcanzar la edad para pensionarse. En mercadeo a esto se le llama "gancho".

Esta propuesta discrepa, claramente de la doctrina de Seguridad Social que pretendía contar con una política particular para cada momento de la vida del trabajador, a fin de atender las vulnerabilidades que enfrenta desde que nace, hasta que fallece.

Es seguro que la mayoría de afiliados harán uso de este "beneficio" sui generis del nuevo enfoque de Seguridad Social salvadoreño, ampliándose así la vulnerabilidad de las personas durante la vejez, ya que, la posibilidad de pagar esas obligaciones será remota para muchos de ellos.

Lo anterior resulta más fácil de comprender, al analizar la aplicación transitoria prevista este beneficio; se plantea que en este año 2017 una persona de 58 años (hombre), podrá efectuar este retiro; teniendo prácticamente 2 años para reintegrarlo; mientras que para el 2018, una persona de 56 años (hombre) podría solicitar este anticipo, teniendo 4 años para reintegrarlo, tal como puede observarse en la siguiente ilustración:

\section{llustración 12: Aplicación transitoria del anticipo de saldo}

\begin{tabular}{ccc}
\hline \multirow{2}{*}{ Años } & \multicolumn{2}{c}{ Edad Cumplida } \\
& Hombres & Mujeres \\
2017 & 58 Años & 53 Años \\
2018 & 56 Años & 51 Años \\
2019 & 54 Años & 49 Años \\
2020 & 52 Años & 47 Años \\
2021 & 50 Años & 45 Años \\
2022 & 48 Años & 41 Años \\
2023 & 46 Años & Cualquier Edad \\
\hline
\end{tabular}

Fuente: Decreto Legislativo 787. 
Lo anterior significa que, las personas próximas a pensionarse diferirán, casi con toda seguridad, el ejercicio de sus derechos a pensionarse por vejez, durante 5 años, a pesar que la Constitución establece que los derechos sociales son irrenunciables y que su ejercicio debería depender, exclusivamente, de su voluntad para hacerlo.

La propuesta consignada en la reforma, además de carecer de base doctrinaria, desde la perspectiva de la Seguridad Social, promueve la postergación del ejercicio de un derecho, por deudas, a raíz del uso de sus propios recursos, lo cual se parece a la pignoración de un depósito a plazos, donde un banco le cobra al depositante por prestarle su propio dinero; en este caso, al trabajador se le penalizaría por utilizar el ahorro que debería usarse, exclusivamente, para pagarle beneficios indemnizatorios futuros.

\section{Devolución de saldo por enfermedad grave}

Mediante el artículo 52 de la reforma se adiciona otro a la Ley del SAP, entre el 126B y el 127, identificándolo como Art. 126C, en el cual se contempla la devolución del saldo a los afiliados que la Comisión Calificadora de Invalidez dictamine con padecimientos graves que comprometan la vida de trabajador.
Esta disposición resulta oportuna, considerando la historia de personas que fallecen durante el primer año de jubilación o durante los primeros 5 , tal como se recoge en la tesis de grado presentada por el autor, en el año 2011, en la Universidad de Alcalá de Henares, en España, para optar por el grado de Master en Dirección y Gestión de Planes y Fondos de Pensiones.

En dicha oportunidad se sostenía que, cuando un pensionado por vejez fuera diagnosticado con una enfermedad terminal, debería recibir el saldo de su cuenta para cubrir sus necesidades inmediatas y mejorar con ello, la calidad de vida en esos momentos.

En el pasado, era imposible entregarle este saldo a los afiliados de una manera distinta a la Renta Programada o cuando el trabajador había sido declarado inválido en el primer dictamen (temporal) o en segundo dictamen (permanente).

Carecía de sentido distribuir el saldo de su cuenta en función de expectativas de vida convencionales, cuando el trabajador había sido diagnosticado con una enfermedad terminal y se disponía de un pronóstico confiable acerca de cuánto podría vivir en esas condiciones; se ilustra a continuación la portada del libro en que fue publicada la tesis de grado antes mencionada, en caso que los lectores tuvieran interés en profundizar en el tema. 


\section{Ilustración 13: Devolución de saldo por enfermedad grave}

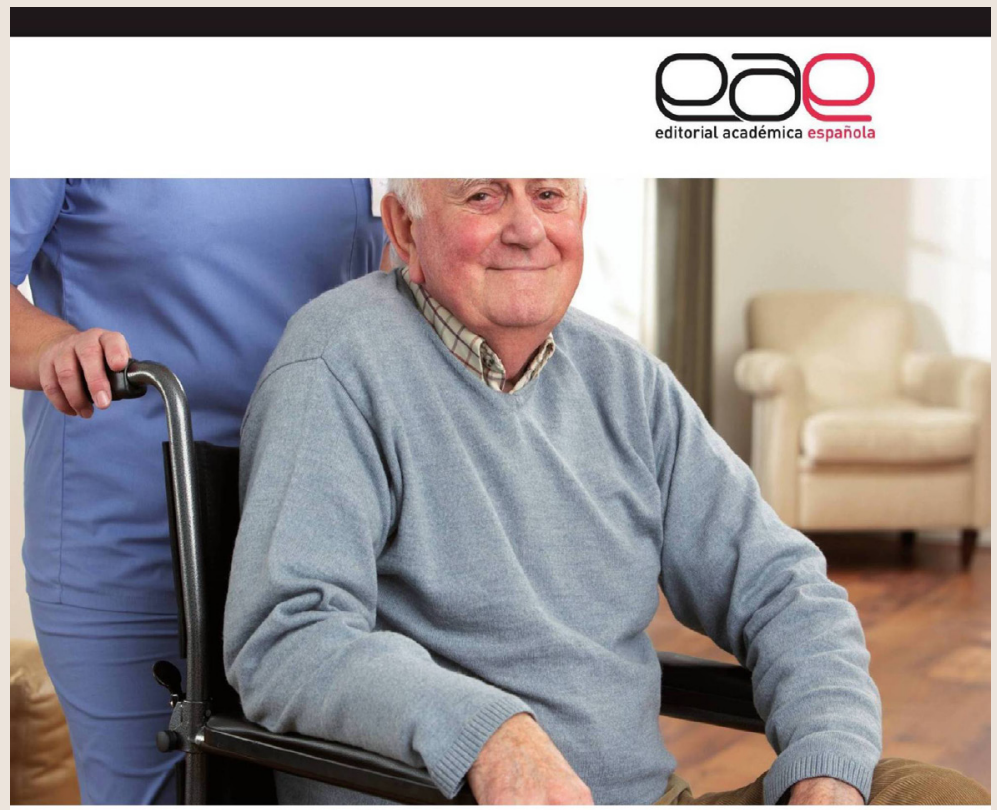

Francisco Sorto Rivas

Pensiones de vejez para enfermos terminales

\section{El caso salvadoreño}

Fuente: Editorial Académica Española

Sin embargo, la forma en que ha quedado redactado el artículo 126-C, se refiere a enfermedades graves, no necesariamente terminales.

Existe la posibilidad, entonces, que el afiliado consuma su saldo y pueda restablecerse después, agotándose previamente los recursos necesarios para cubrir sus necesidades futuras.

Además, no contempla cubrir los estados de necesidad que pudieran enfrentar sus beneficiarios, después de fallecer; a pesar que, se supondría que el saldo remanente quedaría a disposición de ellos. 
Atender esta última situación quedaría, entonces, al arbitrio del trabajador; pero fuera de la tutela de derechos de los beneficiarios ofrecida por la ley.

\section{Devolución de saldo, beneficio económico temporal y beneficio económico permanente}

La reforma reciente a la Ley del SAP abre la posibilidad para que el afiliado que alcance la edad para gozar de una pensión de vejez, pero que no haya acumulado los 25 años de cotización, pueda solicitar la devolución de su saldo o recibir un beneficio alternativo, en función del número de años de cotización registrados hasta esa fecha.

En caso que el afiliado solicite la devolución de su saldo, la ley contempla que la AFP lo hará mediante 3 anualidades sucesivas; tiempo durante el cual el afiliado continuaría gozando de cobertura de salud en el ISSS, siempre y cuando siguiera cotizando, voluntariamente, por dicha cobertura.

De haber cotizado más de 10 años, con un límite máximo de 20 años, el afiliado podrá solicitar un beneficio económico temporal, consistente en la devolución mensual del saldo acumulado, mientras duren los recursos.

El monto de dicho beneficio resultaría de dividir el saldo acumulado entre el número de años cotizados, por 12 .

$$
B E T=\frac{S C L A P}{(\text { No. años cotizados *12) }}
$$

Donde:

BET $=$ Beneficio Económico Temporal. SCIAP $=$ Saldo de la Cuenta Individual de Ahorro para Pensiones.

El valor resultante tendría que compararse con una tabla establecida por el legislador, en función de la Pensión Mínima, tal como sigue:

llustración 14: Porcentaje de pensión mínima reconocida por años de cotización en caso de beneficio temporal

\begin{tabular}{cc}
\hline Años Cotizados & $\%$ PM \\
\hline Hasta 12 & $40 \%$ \\
\hline$[12,14]$ & $45 \%$ \\
{$[14,16]$} & $50 \%$ \\
{$[16,18]$} & $55 \%$ \\
{$[18,20]$} & $60 \%$ \\
\hline
\end{tabular}

Fuente: Decreto 787 
Se escogería el mayor valor, aunque la norma también señala que el afiliado puede solicitar ajustar la mensualidad a la Pensión Mínima de Vejez, hasta agotar el saldo de su CIAP.

El trabajador gozaría de cobertura de salud, de continuar cotizando al ISSS el 7.8\% de la mensualidad asignada.

Además, la norma contempla que, de solicitarse la devolución del saldo acumulado o, de recibirse beneficio económico temporal, al afiliado se le devolverían sus contribuciones a la Cuenta de Garantía Solidaria.

En caso que el trabajador haya cotizado más de 20 años, pero menos de 25 años, podría gozar de beneficio permanente, al distribuírsele el saldo acumulado entre 20 años de anualidades ciertas.
$\mathrm{Al}$ agotarse el saldo de su CIAP, el afiliado gozaría de beneficio de longevidad con cargo a la Cuenta de Garantía Solidaría.

La mensualidad podría ser menor a la Pensión Mínima vigente y el trabajador podría recibir atención médica en el ISSS, de continuar cotizándole al ISSS, el 7.5\% de su mensualidad.

Tanto en el caso del beneficio temporal, como en el permanente, el saldo remanente al fallecer el afiliado formará parte de su haber sucesoral.

A continuación se presenta una ilustración que facilita la comprensión de la regla de devolución de saldo, beneficio temporal y permanente.

\section{Ilustración 15: Beneficios en función del tiempo cotizado en el SAP}

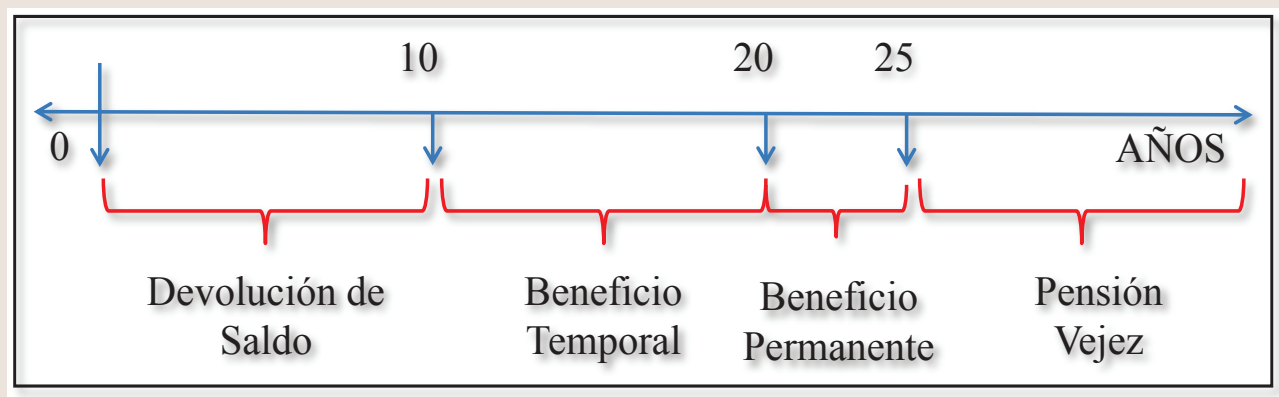

Fuente: Elaboración propia

La opción para obtener un beneficio temporal o permanente dependerá de la voluntad del afiliado que, al cumplir la edad para pensionarse, no reúna el tiempo de cotización necesario para ello.

\section{Pensión por vejez}

La reforma a la Ley del SAP, en materia de pensiones por vejez, se olvidó por completo de la protección del grupo familiar del afi- 
liado, al sacarla del cálculo de la renta programada; originalmente se incluía en el cálculo para preservar parte de la CIAP, para el pago de beneficios por sobrevivencia.

Cuando se promulgó la Ley del SAP, se pensó en proteger al grupo familiar del trabajador, incluyendo las expectativas de vida de todos -al momento en que se pensionaba-, en el cálculo de la Renta Jubilatoria.

Cada familiar tenía un peso relativo distinto en la determinación de la Renta, partiendo del concepto de "Pensión de Referencia", el cual guardaba relación, a su vez, con el evento hipotético de la invalidez del afiliado.
Para incluir la situación familiar de cada trabajador en la determinación de su pensión, se recurría al concepto de Capital Técnico Necesario por unidad de pensión (ctn) ${ }^{11}$, que multiplicado por la pensión de referencia y, por 12, valoraba la expectativa de vida del grupo familiar.

La idea consistía en asegurarse que al fallecer el trabajador, dejara dinero para el pago de pensiones de sobrevivencia.

A continuación se muestra, grosso modo, la fórmula de cálculo de una Renta Programada, en el pasado reciente.

\section{Ilustración 16: Fórmula de cálculo de la renta programada}

$$
\begin{aligned}
& R P=\frac{\text { SCIAP }}{C T N} \\
& C T N=c t n * 12.5 * P R \\
& C T N=\sum c t n * 12.5 * P R \\
& c t n=\frac{N_{x}-\frac{11}{24} D_{x}}{D_{x}} \quad \text { Afiliado } \\
& c t n=\frac{N_{y}-\frac{11}{24} D_{y}}{D_{y}}-\frac{N_{x y}-\frac{11}{24} D_{x y}}{D_{x y}} \quad \text { Cónyuge }
\end{aligned}
$$

Fuente: Elaboración propia

11 Las fórmulas de ctn se determinaban utilizando la teoría actuarial mediante el desarrollo de funciones actuariales y valores conmutativos, los cuales permitían, a partir de una tabla de mortalidad y una tasa de interés, determinar el valor presente de beneficios futuros de una forma rápida y efectiva.

Las tablas de mortalidad y la tasa de interés eran proporcionadas por la Superintendencia del Sistema Financiero, en el pasado reciente.

El factor ctn tomaba diversos valores según la característica del causante de la pensión. 
La Renta Programada se determinaba dividiendo el saldo acumulado (SCIAP) entre el CTN del grupo familiar del pensionado; el cual correspondía al capital necesario para pagar una unidad de pensión, por $12.5^{12}$, por la pensión de referencia correspondiente. Los porcentajes asignados a cada miembro eran distintos y cambiaban, según la existencia de hijos con derechos a pensión o no; además, si éstos eran inválidos o no; considerando también, si había padres que dependieran económicamente del trabajador, etc.

Los Nx y Dx eran valores conmutados extraídos de tablas de mortalidad para hombres y mujeres, con los cuales se determinaba en cada caso, cuántos años tenían de expectativas de vida cada uno, según la edad cumplida al momento de pensionarse el afiliado.

En la ilustración se muestra la forma de calcular el "ctn" del afiliado, por un lado y de la cónyuge, por el otro; dichos ctn se sumaban para establecer el denominador de la fórmula. En la fórmula del cónyuge se restaba la probabilidad de vida simultánea, porque sus derechos se acreditaban al fallecer el afiliado.

Ahora bien, las pensiones se tenían que recalcular todos los años porque el trabajador no compartía el riesgo de longevidad con nadie, lo cual ha cambiado con la reforma del 28 de septiembre, al colectivizarse dicho riesgo en la Cuenta de Garantía Solidaria.

Con esta reforma, carece de sentido hablar de Rentas Vitalicias, ya que su función era precisamente administrar el riesgo de lon- gevidad; ahora esto se hará con la cuenta solidaria.

Cabe señalar entonces, que la reforma cambió la lógica del cálculo de las pensiones de vejez; de anualidades contingentes (probabilísticas) se pasó a rentas ciertas (ordinarias, vencidas), distribuyéndose el saldo acumulado entre anualidades ordinarias por 20 años, es decir, entre los 60 años (hombres) y los 80 años.

Según las tablas de mortalidad utilizadas para calcular el valor de pensión, antes de la reforma, la expectativa de vida de los pensionados era de 11.7 años, al jubilarse; no 20 años $^{13}$.

Hay que tener claro aquí que, no por haber cambiado la regla de cálculo la expectativa de vida de los pensionados se habrá alargado, lo único que se estaría haciendo es distribuyendo, entre más años, los saldos acumulados. De ser así, las pensiones futuras serían menores a las pagadas actualmente.

En caso de vivir más allá de esa edad (80 años los hombres; 75 las mujeres), el pensionado gozaría de un beneficio de longevidad.

1212 mensualidades, más media mensualidad de navidad.

13 No encontré la tabla de mortalidad para mujeres en el Instructivo para la Determinación de los Capitales Técnicos necesarios publicado por la SSF. 


\section{Ilustración 17: Fórmula actual de la renta programada}

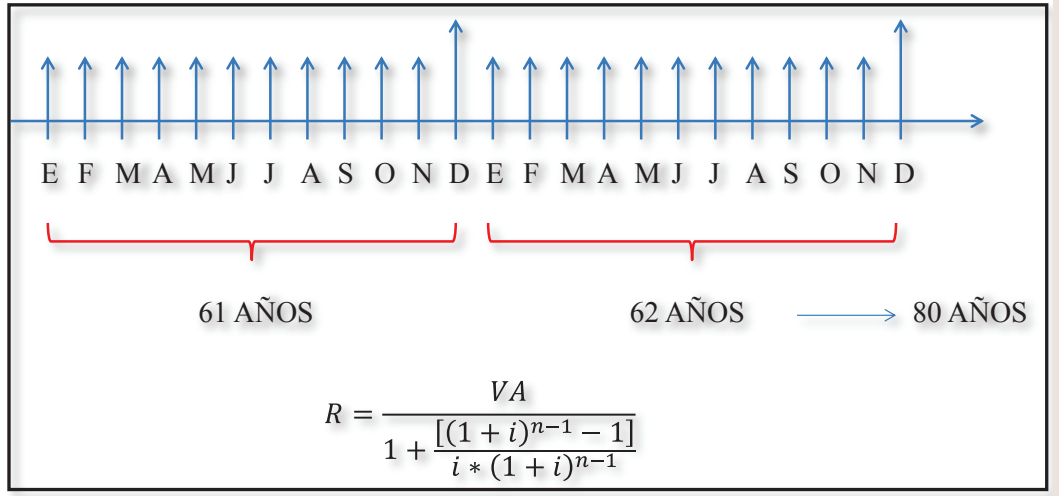

Fuente: Elaboración propia

En la parte inferior de la ilustración anterior se presenta la fórmula para determinar una renta ordinaria anticipada; denominándose ordinaria porque tiene el mismo valor, se paga con la misma frecuencia y porque existe coincidencia, además, entre los períodos de pago y de capitalización.

Es necesario señalar aquí, que el uso de anualidades ciertas no es propio de los sistemas de seguridad social o de la gestión del riesgo de longevidad, ya que lo único cierto es que todos no vamos a morir, aunque no sabemos cuándo.

Es por eso que, la administración de Planes y Fondos de Pensiones se basa en la probabilidad de pagar beneficios ante el fallecimiento de algún asegurado (afiliado) $\mathrm{o}$, tener que hacerlo porque éste no ha fallecido (Rentas).

\section{Contratación de seguro de invalidez y sobrevivencia}

La reforma a la Ley del SAP preserva la contratación de pólizas de vida, con alguna aseguradora autorizada por la Superintendencia del Sistema Financiero, para brindar cobertura al Sistema de Ahorro para Pensiones, modificando esencialmente las pensiones de referencia utilizadas para determinar el capital complementario que corresponde al pago de reclamos presentados por la aseguradora, en nombre de los asegurados, ante la ocurrencia de dos tipos de eventos; sufrir alguna invalidez antes de alcanzar la edad para pensionarse, por riesgos comunes. Los riesgos profesionales los cubre el Instituto Salvadoreño del Seguro Social (ISSS). También se cubriría con la póliza el fallecimiento del afiliado antes de pensionarse, pero siempre por riesgo común. 
Originalmente, la base para el cálculo de los beneficios era el 70\% del Salario Básico Regulador (SBR; el promedio de los 120 últimos salarios del afiliado), en caso de invalidez total; mientras que para la invalidez parcial, el porcentaje era del 50\% del SBR.

En la actualidad, el porcentaje reconocido por invalidez total es del 50\% del SBR y, para invalidez parcial, el porcentaje bajó al 36\%.

Este beneficio se calcula siempre como la diferencia entre el saldo acumulado y el valor necesario para pagarles pensión a los trabajadores y sus familias.

Las pensiones de sobrevivencias continúan determinándose a partir de la pensión de un inválido total, según el Art. 121 de la Ley; éste no se modificó, aunque al haberse suprimido los criterios actuariales para los capitales técnicos necesarios, se tendría que desarrollar alguna norma de coordinación con lo dispuesto para la Cuenta de Garantía Solidaria.

Sería necesario evaluar cómo se verían impactadas las primas de seguro por la reducción de las pensiones de referencia, en contraposición con la ampliación del período para gozar de una pensión por vejez.

Daría la impresión, en todo caso, que las primas de seguro deberían bajar, ya que el valor de los capitales complementarios también se ajustó. De ser así, las comisiones netas por la administración de cuentas podrían aumentar.
Este es otro tema que no ha quedado adecuadamente desarrollado en la reforma, ni cuantificado por supuesto, por lo que resulta difícil identificar posibles subsidios cruzados entre beneficios, costos e intereses corporativos.

\section{Reducción del monto de la pensiones de la población optada SAP}

La población optada del SAP corresponde a todas aquellas personas que a la entrada en funcionamiento el SAP (Abril de 1998) tenían más de 36 años de edad, pero menos de 55 años, los hombres; así como las mujeres que más de 36 años, pero menos de 50 años de edad.

Cuando se implementó el sistema actual, el legislador ofreció a estas personas la oportunidad de permanecer en el sistema antiguo (SPP) o traspasarse al nuevo (SAP), en función del modelo previsional que le resultara más conveniente.

Cuando el afiliado no optó por permanecer en el SPP, en el tiempo establecido para ello $^{14}$, se le traspasó forzosamente al SAP.

La edad máxima para optar por permanecer en el SPP se fijó tomando en cuenta el impacto que tendría la capitalización de aportes, sobre el ahorro acumulado de los

14 Inicialmente fueron 6 meses, pero luego se amplió el plazo para ejercer el derecho de optar por permanecer en el SAP, 6 meses más. 
trabajadores y, por ende, sobre el valor de sus pensiones futuras.

Se consideró, en esa oportunidad, que 5 años eran insuficientes para que, al traspasarse al SAP, las pensiones de los optados del SAP, superaran las ofrecidas por el esquema anterior, quedando obligados así, a permanecer en el sistema público (SPP) los trabajadores próximos a jubilarse.

En las condiciones vigentes en esa oportunidad (1998) y las facilidades que se les dio a las AFP para afiliar a los trabajadores, se registró un traspaso masivo de cotizantes al nuevo modelo previsional. ${ }^{15}$

Se entiende, entonces, que se pretendía ofrecer a los optados las mejores condiciones de retiro posible.

Por otra parte, hay que recordar que la dolarización de la economía se dio en el año 2001, siendo las tasas de interés previas del orden de los 2 dígitos; eso hacía que las proyecciones de acumulación de ahorros para el retiro prometieran pensiones superiores a las otorgadas en el régimen antiguo, ya que dichos intereses eran mayores a la tasa de interés técnico utilizada para determinar los capitales técnicos necesarios por unidad de pensión ( $6 \%$ anual).

Como las condiciones cambiaron y hubo personas que permanecieron en sistema anterior, en contraposición con aquellos que se traspasaron voluntaria u obligatoriamente al SAP, los montos de las pensiones discreparon entre sistemas; en el SPP resul- taban superiores que en el SAP, a pesar que las condiciones de tiempo cotizado y SBR reportados por los trabajadores, de diferente régimen, podían ser similares.

Fue por esa razón que se expresaron inconformidades entre los pensionados del SAP y cierta sensación de engaño y frustración, lo cual dio pie a que durante la administración del Presidente Flores se promulgara el DL 1217, orientado a equiparar el monto de las pensiones entre sistemas, mediante el reconocimiento de un Certificado de Traspaso Complementario, cuyas características eran similares a los títulos valores emitidos a favor de los trabajadores que se traspasaron al SAP, en concepto de bono de reconocimiento por el tiempo cotizado en el sistema de reparto (Certificado de Traspaso; CT).

En el año 2006, durante el Gobierno del Presidente Saca, se enfrentaban dificultades para pagar las pensiones del sistema público, por lo que creó el Fideicomiso de Obligaciones Previsionales para colocar deuda a los Fondos de Pensiones, hacer caja y con ello, pagar las pensiones en curso del régimen anterior.

En esa oportunidad se aprovechó para convertir las obligaciones de equiparación de pensiones (DL 1217), en Rentas Vitalicias públicas, mediante la aprobación del DL 100 , con lo cual se creaba una categoría de pensionados distinta a los del DL 1217, a quienes se les emitió CTC.

15 Los institutos públicos destinaron pocos recursos a la promoción de la permanencia en el SPP entre la población cotizante. 
Con la reforma de septiembre de este año (2017), se redujeron las pensiones para los afiliados optados, tanto para los que aún no se han pensionado, como para aquellos que sí gozan de pensión. Sin embargo, la reforma favoreció a los pensionados del DL 1217, a quienes se les reconocerá pensión con cargo a la CGS cuando se les agote el saldo de sus cuentas, a pesar que con la entrega del CTC, las obligaciones que tenía el Estado con ellos quedaba saldado.

Indistintamente de compartir o no el sentido social de dicha disposición, ésta carece de sustentación jurídica, ya que si el Estado ya no tenía obligaciones con ellos, no debería creárselas a los cotizantes del SAP, a través de la CGS.

La base de comparación para la determinación del derecho a la equiparación de pensiones entre sistemas era la tasa de reemplazo (TR) utilizada para pensiones de invalidez total, que según el artículo 197 reconocería al trabajador, $30 \%$ del SBR por los primeros 3 años cotizados, más $1.5 \%$ por cada año adicional; sin exceder del 100\%. Esto último considerando que las pensiones constituyen fuentes sustitutivas del salario de los trabajadores. No se justificaría tener pensiones superiores a los salarios devengados por los afiliados, antes de jubilarse.

La nueva norma reconoce el 35\% para los primeros 10 años, más $1 \%$ para los siguientes, sin exceder del 55\% del SBR, ni los $\$ 2,000$ de pensión mensual; en otras palabras, la tasa de reemplazo hoy está sujeta a una doble restricción; una relativa $(55 \%$ del
SBR, como máximo) y otra absoluta $(\$ 2,000$ de pensión mensual).

La fórmula de tiempo cotizado, para el pago de pensión, trataba de estimular la permanencia de los trabajadores en el sistema ${ }^{16}$, por lo que la tasa de reemplazo carecía de límites; hoy no, si se requiere de 25 años cotizados y 60 años de edad para pensionarse, en el caso de los hombres, la tasa de reemplazo reconocida sería del 50\% del SBR.

De ahí que, después de los 30 años de cotización ya no se continuaría acumulando derechos, en términos de TR, aunque sí podría mejorar el SBR; aunque el monto de la pensión sólo aumentaría si el cálculo preliminar fuera inferior a los $\$ 2,000$.

No obstante lo anterior, habría que preguntarse cuál fue la base doctrinaria para definir un período de carencia de 10 años para el cálculo de la TR o para fijar el 55\% del SBR, como tope; más allá del simple interés de reducir parcialmente las obligaciones del Estado. De ser esta último la principal motivación de la reforma, me parece demasiado alambicado el procedimiento para hacerlo; ya que la TR comienza realmente en 50\% del SBR para todos los trabajadores con derecho a pensión, para el universo de afiliados de SBR de $\$ 4,000$ mensuales, hacia abajo.

16 También tiene sentido en sociedades donde se permite la jubilación anticipada, con un porcentaje de pensión reducido, como es en los Estados Unidos, por ejemplo. 
De manera gráfica, el cambio realizado mediante la reforma, para rebajar el monto de las pensiones de los optados, se presenta a continuación.

\section{Ilustración 18: Tasa de reemplazo}

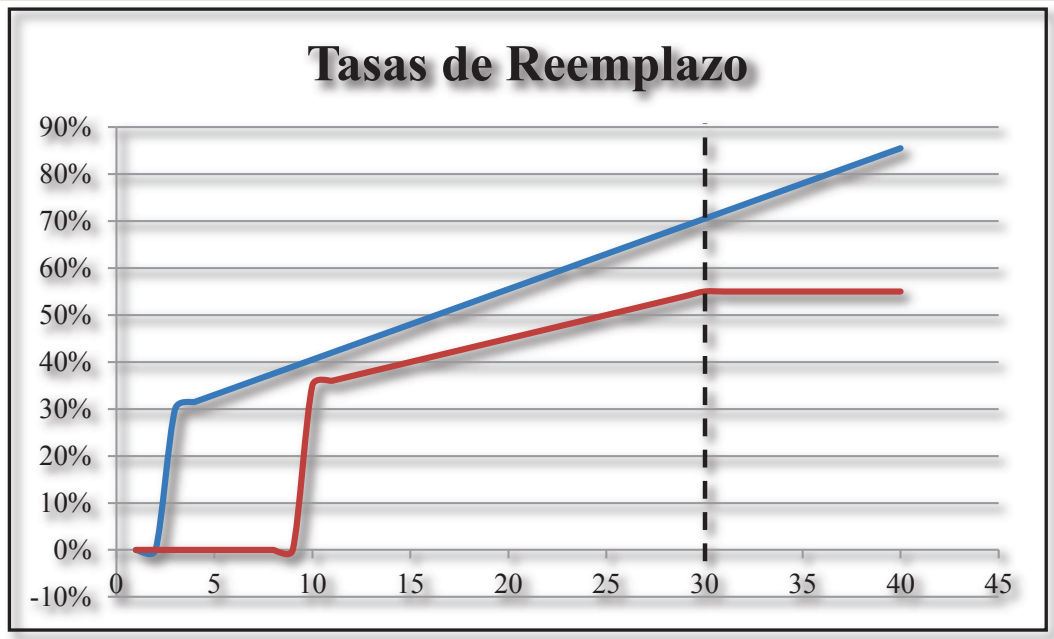

Fuente: Elaboración propia

En el eje horizontal (abscisas) se muestran los años cotizados y en el vertical (ordenadas), el porcentaje de SBR reconocido; a la altura de los 30 años cotizados, la tasa de reemplazo deja de crecer. La brecha entre ambas curvas sugiere el impacto que tendrá la reforma sobre la pensión de los optados del SAP.
El impacto de la doble restricción sobre las pensiones de los optados se muestra a continuación.

El artículo 197 de la Ley del SAP fijaba tasas de reemplazo que comenzaban en 30\% para los primeros 3 años, más 1.5\% adicional por año; a los 25 años los optados tenían derecho al 63\% del SBR; a los 30 años de cotización, del $71 \%$. 
Ilustración 19: Montos de pensión para los optados, antes de la reforma

\begin{tabular}{|c|c|c|c|c|c|c|c|c|c|}
\hline Taza de reemplazo & $63 \%$ & $65 \%$ & $66 \%$ & $68 \%$ & $69 \%$ & $71 \%$ & $72 \%$ & $74 \%$ & $75 \%$ \\
\hline $\begin{array}{c}\text { Salarios/Años } \\
\text { Cotizados }\end{array}$ & 25 & 26 & 27 & 28 & 29 & 30 & 31 & 32 & 33 \\
\hline$\$ 300$ & $\$ 207,6$ & $\$ 207,6$ & $\$ 207,6$ & $\$ 207,6$ & $\$ 207,6$ & $\$ 211,5$ & $\$ 216,0$ & $\$ 220,5$ & $\$ 225,0$ \\
\hline$\$ 550$ & $\$ 346,5$ & $\$ 354,8$ & $\$ 363,0$ & $\$ 371,3$ & $\$ 379,5$ & $\$ 387,8$ & $\$ 396,0$ & $\$ 404,3$ & $\$ 412,5$ \\
\hline$\$ 800$ & $\$ 504,0$ & $\$ 516,0$ & $\$ 528,0$ & $\$ 540,0$ & $\$ 552,0$ & $\$ 564,0$ & $\$ 576,0$ & $\$ 588,0$ & $\$ 600,0$ \\
\hline$\$ 1.050$ & $\$ 661,5$ & $\$ 677,3$ & $\$ 693,0$ & $\$ 708,8$ & $\$ 724,5$ & $\$ 740,3$ & $\$ 756,0$ & $\$ 771,8$ & $\$ 787,5$ \\
\hline$\$ 1.300$ & $\$ 819,0$ & $\$ 838,5$ & $\$ 858,0$ & $\$ 877,5$ & $\$ 897,0$ & $\$ 916,5$ & $\$ 936,0$ & $\$ 955,5$ & $\$ 975,0$ \\
\hline$\$ 1.550$ & $\$ 976,5$ & $\$ 999,8$ & $\$ 1.023,0$ & $\$ 1.046,3$ & $\$ 1.069,5$ & $\$ 1.092,8$ & $\$ 1.116,0$ & $\$ 1.139,3$ & $\$ 1.162,5$ \\
\hline$\$ 1.800$ & $\$ 1.134,0$ & $\$ 1.161,0$ & $\$ 1.188,0$ & $\$ 1.215,0$ & $\$ 1.242,0$ & $\$ 1.269,0$ & $\$ 1.296,0$ & $\$ 1.323,0$ & $\$ 1.350,0$ \\
\hline$\$ 2.050$ & $\$ 1.291,5$ & $\$ 1.322,3$ & $\$ 1.353,0$ & $\$ 1.383,8$ & $\$ 1.414,5$ & $\$ 1.445,3$ & $\$ 1.476,0$ & $\$ 1.506,8$ & $\$ 1.537,5$ \\
\hline$\$ 2.300$ & $\$ 1.449,0$ & $\$ 1.483,5$ & $\$ 1.518,0$ & $\$ 1.552,5$ & $\$ 1.587,0$ & $\$ 1.621,5$ & $\$ 1.656,0$ & $\$ 1.690,5$ & $\$ 1.725,0$ \\
\hline$\$ 2.550$ & $\$ 1.606,5$ & $\$ 1.644,8$ & $\$ 1.683,0$ & $\$ 1.721,3$ & $\$ 1.759,5$ & $\$ 1.797,8$ & $\$ 1.836,0$ & $\$ 1.874,3$ & $\$ 1.912,5$ \\
\hline$\$ 2.800$ & $\$ 1.764,0$ & $\$ 1.806,0$ & $\$ 1.848,0$ & $\$ 1.890,0$ & $\$ 1.932,0$ & $\$ 1.974,0$ & $\$ 2.016,0$ & $\$ 2.058,0$ & $\$ 2.100,0$ \\
\hline$\$ 3.050$ & $\$ 1.921,5$ & $\$ 1.967,3$ & $\$ 2.013,0$ & $\$ 2.058,8$ & $\$ 2.104,5$ & $\$ 2.150,3$ & $\$ 2.196,0$ & $\$ 2.241,8$ & $\$ 2.287,5$ \\
\hline$\$ 3.300$ & $\$ 2.079,0$ & $\$ 2.128,5$ & $\$ 2.178,0$ & $\$ 2.227,5$ & $\$ 2.277,0$ & $\$ 2.326,5$ & $\$ 2.376,0$ & $\$ 2.425,5$ & $\$ 2.475,0$ \\
\hline$\$ 3.550$ & $\$ 2.236,5$ & $\$ 2.289,8$ & $\$ 2.343,0$ & $\$ 2.396,3$ & $\$ 2.449,5$ & $\$ 2.502,8$ & $\$ 2.556,0$ & $\$ 2.609,3$ & $\$ 2.662,5$ \\
\hline$\$ 3.800$ & $\$ 2.394,0$ & $\$ 2.451,0$ & $\$ 2.508,0$ & $\$ 2.565,0$ & $\$ 2.622,0$ & $\$ 2.679,0$ & $\$ 2.736,0$ & $\$ 2.793,0$ & $\$ 2.850,0$ \\
\hline$\$ 4.050$ & $\$ 2.551,5$ & $\$ 2.612,3$ & $\$ 2.673,0$ & $\$ 2.733,8$ & $\$ 2.794,5$ & $\$ 2.855,3$ & $\$ 2.916,0$ & $\$ 2.976,8$ & $\$ 3.037,5$ \\
\hline$\$ 4.300$ & $\$ 2.709,0$ & $\$ 2.773,5$ & $\$ 2.838,0$ & $\$ 2.902,5$ & $\$ 2.967,0$ & $\$ 3.031,5$ & $\$ 3.096,0$ & $\$ 3.160,5$ & $\$ 3.225,0$ \\
\hline$\$ 4.550$ & $\$ 2.866,5$ & $\$ 2.934,8$ & $\$ 3.003,0$ & $\$ 3.071,3$ & $\$ 3.139,5$ & $\$ 3.207,8$ & $\$ 3.276,0$ & $\$ 3.344,3$ & $\$ 3.412,5$ \\
\hline$\$ 4.800$ & $\$ 3.024,0$ & $\$ 3.096,0$ & $\$ 3.168,0$ & $\$ 3.240,0$ & $\$ 3.312,0$ & $\$ 3.384,0$ & $\$ 3.456,0$ & $\$ 3.528,0$ & $\$ 3.600,0$ \\
\hline$\$ 5.050$ & $\$ 3.181,5$ & $\$ 3.257,3$ & $\$ 3.333,0$ & $\$ 3.408,8$ & $\$ 3.484,5$ & $\$ 3.560,3$ & $\$ 3.636,0$ & $\$ 3.711,8$ & $\$ 3.787,5$ \\
\hline$\$ 5.300$ & $\$ 3.339,0$ & $\$ 3.418,5$ & $\$ 3.498,0$ & $\$ 3.577,5$ & $\$ 3.657,0$ & $\$ 3.736,5$ & $\$ 3.816,0$ & $\$ 3.895,5$ & $\$ 3.975,0$ \\
\hline$\$ 5.550$ & $\$ 3.496,5$ & $\$ 3.579,8$ & $\$ 3.663,0$ & $\$ 3.746,3$ & $\$ 3.829,5$ & $\$ 3.912,8$ & $\$ 3.996,0$ & $\$ 4.079,3$ & $\$ 4.162,5$ \\
\hline$\$ 5.800$ & $\$ 3.654,0$ & $\$ 3.741,0$ & $\$ 3.828,0$ & $\$ 3.915,0$ & $\$ 4.002,0$ & $\$ 4.089,0$ & $\$ 4.176,0$ & $\$ 4.263,0$ & $\$ 4.350,0$ \\
\hline$\$ 6.050$ & $\$ 3.811,5$ & $\$ 3.902,3$ & $\$ 3.993,0$ & $\$ 4.083,8$ & $\$ 4.174,5$ & $\$ 4.265,3$ & $\$ 4.356,0$ & $\$ 4.446,8$ & $\$ 4.537,5$ \\
\hline$\$ 6.300$ & $\$ 3.969,0$ & $\$ 4.063,5$ & $\$ 4.158,0$ & $\$ 4.252,5$ & $\$ 4.347,0$ & $\$ 4.441,5$ & $\$ 4.536,0$ & $\$ 4.630,5$ & $\$ 4.725,0$ \\
\hline$\$ 6.550$ & $\$ 4.126,5$ & $\$ 4.224,8$ & $\$ 4.323,0$ & $\$ 4.421,3$ & $\$ 4.519,5$ & $\$ 4.617,8$ & $\$ 4.716,0$ & $\$ 4.814,3$ & $\$ 4.912,5$ \\
\hline$\$ 6.800$ & $\$ 4.284,0$ & $\$ 4.386,0$ & $\$ 4.488,0$ & $\$ 4.590,0$ & $\$ 4.692,0$ & $\$ 4.794,0$ & $\$ 4.896,0$ & $\$ 4.998,0$ & $\$ 5.100,0$ \\
\hline
\end{tabular}

Fuente: Elaboración propia

Para un SBR de $\$ 300$, la pensión para 25 años cotizados era de $\$ 207.6$ (valor de la pensión mínima de vejez); cambiando únicamente hasta los 30 de cotización; para alguien que ganara $\$ 4,050$ de SBR, obten- dría una pensión de $\$ 2,551.5$, por 25 años cotizados y de $\$ 3,037.5$ al haber cotizado 33 años.

Qué sucede con las condiciones actuales. 


\section{Ilustración 20: Montos de pensión para los optados, antes de la reforma}

\begin{tabular}{|c|c|c|c|c|c|c|c|c|c|}
\hline Tasa de reemplazo & $50 \%$ & $51 \%$ & $52 \%$ & $53 \%$ & $54 \%$ & $55 \%$ & $55 \%$ & $55 \%$ & $55 \%$ \\
\hline $\begin{array}{c}\text { Salarios/Años } \\
\text { Cotizados }\end{array}$ & 25 & 26 & 27 & 28 & 29 & 30 & 31 & 32 & 33 \\
\hline$\$ 300$ & $\$ 207,60$ & $\$ 207,60$ & $\$ 207,60$ & $\$ 207,60$ & $\$ 207,60$ & $\$ 207,60$ & $\$ 207,60$ & $\$ 207,60$ & $\$ 207,60$ \\
\hline$\$ 550$ & $\$ 275,00$ & $\$ 280,50$ & $\$ 286,00$ & $\$ 291,50$ & $\$ 297,00$ & $\$ 302,50$ & $\$ 302,50$ & $\$ 302,50$ & $\$ 302,50$ \\
\hline$\$ 800$ & $\$ 400,00$ & $\$ 408,00$ & $\$ 416,00$ & $\$ 424,00$ & $\$ 432,00$ & $\$ 440,00$ & $\$ 440,00$ & $\$ 440,00$ & $\$ 440,00$ \\
\hline$\$ 1.050$ & $\$ 525,00$ & $\$ 535,50$ & $\$ 546,00$ & $\$ 556,50$ & $\$ 567,00$ & $\$ 577,50$ & $\$ 577,50$ & $\$ 577,50$ & $\$ 577,50$ \\
\hline$\$ 1.300$ & $\$ 650,00$ & $\$ 663,00$ & $\$ 676,00$ & $\$ 689,00$ & $\$ 702,00$ & $\$ 715,00$ & $\$ 715,00$ & $\$ 715,00$ & $\$ 715,00$ \\
\hline$\$ 1.550$ & $\$ 775,00$ & $\$ 790,50$ & $\$ 806,00$ & $\$ 821,50$ & $\$ 837,00$ & $\$ 852,50$ & $\$ 852,50$ & $\$ 852,50$ & $\$ 852,50$ \\
\hline$\$ 1.800$ & $\$ 900,00$ & $\$ 918,00$ & $\$ 936,00$ & $\$ 954,00$ & $\$ 972$ & $\$ 990,00$ & $\$ 990,00$ & $\$ 990,00$ & $\$ 990,00$ \\
\hline$\$ 2.050$ & $1.025,00$ & $\$ 1.045,50$ & $\$ 1.066,00$ & $\$ 1.086,50$ & $\$ 1.107,00$ & $\$ 1.127,50$ & $\$ 1.127,50$ & $\$ 1.127,50$ & $\$ 1.127,50$ \\
\hline$\$ 2.300$ & $1.150,00$ & $\$ 1.173,00$ & $\$ 1.196,00$ & $1.219,00$ & $\$ 1.242,00$ & $\$ 1.265,00$ & $\$ 1.265,00$ & $\$ 1.265,00$ & $\$ 1.265,00$ \\
\hline$\$ 2.550$ & & & $\$ 1.326,00$ & $\$ 1.351,50$ & & & & & $\$ 1.402,50$ \\
\hline$\$ 2.800$ & $\$ 1.400,00$ & $\$ 1.428,00$ & $\$ 1.456,00$ & $\$ 1.484,00$ & $\$ 1.512,00$ & $\$ 1.540,00$ & $\$ 1.540,00$ & $\$ 1.540,00$ & $\$ 1.540,00$ \\
\hline$\$ 3.050$ & $1.525,00$ & $\$ 1.555,50$ & $\$ 1.586,00$ & $\$ 1.616,50$ & $\$ 1.647,00$ & $\$ 1.677,50$ & $\$ 1.677,50$ & $\$ 1.677,50$ & $\$ 1.677,50$ \\
\hline & & & & & & & & & \\
\hline$\$ 3.550$ & $.775,00$ & $\$ 1.810,50$ & $\$ 1.846,00$ & $\$ 1.881,50$ & $\$ 1.917,00$ & $\$ 1.952,50$ & $\$ 1.952,50$ & $\$ 1.952,50$ & $\$ 1.952,50$ \\
\hline$\$ 3.800$ & $\$ 1.900,00$ & $\$ 1.938,00$ & $\$ 1.976,00$ & $\$ 2.000,00$ & $\$ 2.000,00$ & $\$ 2.000,00$ & $\$ 2.000,00$ & $\$ 2.000,00$ & $\$ 2.000,00$ \\
\hline$\$ 4.050$ & $\$ 2.000,00$ & $\$ 2.000,00$ & $\$ 2.000,00$ & $\$ 2.000,00$ & $\$ 2.000,00$ & $\$ 2.000,00$ & $\$ 2.000,00$ & $\$ 2.000,00$ & $\$ 2.000,00$ \\
\hline$\$ 4.300$ & $\$ 2.000,00$ & $\$ 2.000,00$ & $\$ 2.000,00$ & $\$ 2.000,00$ & $\$ 2.000,00$ & $\$ 2.000,00$ & $\$ 2.000,00$ & $\$ 2.000,00$ & $\$ 2.000,00$ \\
\hline$\$ 4.550$ & & $\$ 2.000,00$ & $\$ 2.000,00$ & $\$ 2.000,00$ & $\$ 2.000,00$ & & &, 00 & $\$ 2.000,00$ \\
\hline$\$ 4.800$ & $\$ 2.000,00$ & $\$ 2.000,00$ & $\$ 2.000,00$ & $\$ 2.000,00$ & $\$ 2.000,00$ & $\$ 2.000,00$ & $\$ 2.000,00$ & $\$ 2.000,00$ & $\$ 2.000,00$ \\
\hline$\$ 5.050$ & $\$ 2.000,00$ & $\$ 2.000,00$ & $\$ 2.000,00$ & $\$ 2.000,00$ & $\$ 2.000,00$ & $\$ 2.000,00$ & $\$ 2.000,00$ & $\$ 2.000,00$ & $\$ 2.000,00$ \\
\hline$\$ 5.300$ & $\$ 2.000,00$ & $\$ 2.000,00$ & $\$ 2.000,00$ & $\$ 2.000,00$ & $\$ 2.000,00$ & $\$ 2.000,00$ & $\$ 2.000,00$ & $\$ 2.000,00$ & $\$ 2.000,00$ \\
\hline$\$ 5.550$ & $\$ 2.000,00$ & $\$ 2.000,00$ & $\$ 2.000,00$ & $\$ 2.000,00$ & $\$ 2.000,00$ & $\$ 2.000,00$ & $\$ 2.000,00$ & $\$ 2.000,00$ & $\$ 2.000,00$ \\
\hline$\$ 5.800$ & $\$ 2.000,00$ & $\$ 2.000,00$ & $\$ 2.000,00$ & $\$ 2.000,00$ & $\$ 2.000,00$ & $\$ 2.000,00$ & $\$ 2.000,00$ & $\$ 2.000,00$ & $\$ 2.000,00$ \\
\hline$\$ 6.050$ & $\$ 2.000,00$ & $\$ 2.000,00$ & $\$ 2.000,00$ & $\$ 2.000,00$ & $\$ 2.000,00$ & $\$ 2.000,00$ & $\$ 2.000,00$ & $\$ 2.000,00$ & $\$ 2.000,00$ \\
\hline$\$ 6.300$ & $\$ 2.000,00$ & $\$ 2.000,00$ & $\$ 2.000,00$ & $\$ 2.000,00$ & $\$ 2.000,00$ & $\$ 2.000,00$ & $\$ 2.000,00$ & $\$ 2.000,00$ & $\$ 2.000,00$ \\
\hline$\$ 6.550$ & $\$ 2.000,00$ & $\$ 2.000,00$ & $\$ 2.000,00$ & $\$ 2.000,00$ & $\$ 2.000,00$ & $\$ 2.000,00$ & $\$ 2.000,00$ & $\$ 2.000,00$ & $\$ 2.000,00$ \\
\hline$\$ 6.800$ & $\$ 2.000,00$ & $\$ 2.000,00$ & $\$ 2.000,00$ & $\$ 2.000,00$ & $\$ 2.000,00$ & $\$ 2.000,00$ & $\$ 2.000,00$ & $\$ 2.000,00$ & $\$ 2.000,00$ \\
\hline
\end{tabular}

Fuente: Elaboración propia

Para un SBR de $\$ 300$ no existe ningún cambio, aunque a partir de los 30 años cotizados el afiliado recibía un poco más de la pensión mínima; para aquellos afiliados con SBR de $\$ 4,050$, el monto de la pensión sería de $\$ 2,000$, indistintamente del número de años que haya cotizado. Lo mismo sucederá con los cotizantes con SBR superiores, tal como se puede apreciar en la ilustración anterior, donde se ha coloreado la tabla con pensiones tope.

La pérdida de beneficios sería, por lo tanto, la siguiente: 


\section{Ilustración 21: Reducción en el monto de pensión para los optados}

\begin{tabular}{|c|c|c|c|c|c|c|c|c|c|}
\hline Tasa de reemplazo & $63 \%$ & $65 \%$ & $66 \%$ & $68 \%$ & $69 \%$ & $71 \%$ & $72 \%$ & $74 \%$ & $75 \%$ \\
\hline $\begin{array}{c}\text { Salarios/Años } \\
\text { Cotizados }\end{array}$ & 25 & 26 & 27 & 28 & 29 & 30 & 31 & 32 & 33 \\
\hline$\$ 300$ & $\$ 0.0$ & $\$ 0.0$ & $\$ 0.0$ & $\$ 0.0$ & $\$ 0.0$ & $\$ 3.9$ & $\$ 8.4$ & $\$ 12.9$ & $\$ 17.4$ \\
\hline$\$ 550$ & $\$ 71.5$ & $\$ 74.3$ & $\$ 77.0$ & $\$ 79.8$ & $\$ 82.5$ & $\$ 85.3$ & $\$ 93.5$ & $\$ 101.8$ & $\$ 110.0$ \\
\hline$\$ 800$ & $\$ 104.0$ & $\$ 108.0$ & $\$ 112.0$ & $\$ 116.0$ & $\$ 120.0$ & $\$ 124.0$ & $\$ 136.0$ & $\$ 148.0$ & $\$ 160.0$ \\
\hline$\$ 1,050$ & $\$ 136.5$ & $\$ 141.8$ & $\$ 147.0$ & $\$ 152.3$ & $\$ 157.5$ & $\$ 162.8$ & $\$ 178.5$ & $\$ 194.3$ & $\$ 210.0$ \\
\hline$\$ 1,300$ & $\$ 169.0$ & $\$ 175.5$ & $\$ 182.0$ & $\$ 188.5$ & $\$ 195.0$ & $\$ 201.5$ & $\$ 221.0$ & $\$ 240.5$ & $\$ 260.0$ \\
\hline$\$ 1,550$ & $\$ 201.5$ & $\$ 209.3$ & $\$ 217.0$ & $\$ 224.8$ & $\$ 232.5$ & $\$ 240.3$ & $\$ 263.5$ & $\$ 286.8$ & $\$ 310.0$ \\
\hline$\$ 1,800$ & $\$ 234.0$ & $\$ 243.0$ & $\$ 252.0$ & $\$ 261.0$ & $\$ 270.0$ & $\$ 279.0$ & $\$ 306.0$ & $\$ 333.0$ & $\$ 360.0$ \\
\hline$\$ 2,050$ & $\$ 266.5$ & $\$ 276.8$ & $\$ 287.0$ & $\$ 297.3$ & $\$ 307.5$ & $\$ 317.8$ & $\$ 348.5$ & $\$ 379.3$ & $\$ 410.0$ \\
\hline$\$ 2,300$ & $\$ 299.0$ & $\$ 310.5$ & $\$ 322.0$ & $\$ 333.5$ & $\$ 345.0$ & $\$ 356.5$ & $\$ 391.0$ & $\$ 425.5$ & $\$ 460.0$ \\
\hline$\$ 2,550$ & $\$ 331.5$ & $\$ 344.3$ & $\$ 357.0$ & $\$ 369.8$ & $\$ 382.5$ & $\$ 395.3$ & $\$ 433.5$ & $\$ 471.8$ & $\$ 510.0$ \\
\hline$\$ 2,800$ & $\$ 364.0$ & $\$ 378.0$ & $\$ 392.0$ & $\$ 406.0$ & $\$ 420.0$ & $\$ 434.0$ & $\$ 476.0$ & $\$ 518.0$ & $\$ 560.0$ \\
\hline$\$ 3,050$ & $\$ 396.5$ & $\$ 411.8$ & $\$ 427.0$ & $\$ 442.3$ & $\$ 457.5$ & & & & $\$ 610.0$ \\
\hline$\$ 3,300$ & $\$ 429.0$ & $\$ 445.5$ & $\$ 462.0$ & $\$ 478.5$ & $\$ 495.0$ & $\$ 511.5$ & $\$ 561.0$ & $\$ 610.5$ & $\$ 660.0$ \\
\hline$\$ 3,550$ & $\$ 461.5$ & $\$ 479.3$ & $\$ 497.0$ & $\$ 514.8$ & $\$ 532.5$ & $\$ 550.3$ & $\$ 603.5$ & $\$ 656.8$ & $\$ 710.0$ \\
\hline$\$ 3,800$ & $\$ 494.0$ & $\$ 513.0$ & $\$ 532.0$ & $\$ 565.0$ & $\$ 622.0$ & $\$ 679.0$ & $\$ 736.0$ & $\$ 793.0$ & $\$ 850.0$ \\
\hline$\$ 4,050$ & $\$ 551.5$ & $\$ 612.3$ & $\$ 673.0$ & $\$ 733.8$ & $\$ 794.5$ & $\$ 855.3$ & $\$ 916.0$ & $\$ 976.8$ & $\$ 1,037.5$ \\
\hline$\$ 4,300$ & $\$ 709.0$ & $\$ 773.5$ & $\$ 838.0$ & $\$ 902.5$ & $\$ 967.0$ & $\$ 1,031.5$ & $\$ 1,096.0$ & $\$ 1,160.5$ & $\$ 1,225.0$ \\
\hline$\$ 4,550$ & $\$ 866.5$ & $\$ 934.8$ & $\$ 1,003.0$ & $\$ 1,071.3$ & $\$ 1,139.5$ & $\$ 1,207.8$ & $\$ 1,276.0$ & $\$ 1,344.3$ & $\$ 1,412.5$ \\
\hline$\$ 4,800$ & $\$ 1,024.0$ & $\$ 1,096.0$ & $\$ 1,168.0$ & $\$ 1,240.0$ & $\$ 1,312.0$ & $\$ 1,384.0$ & $\$ 1,456.0$ & $\$ 1,528.0$ & $\$ 1,600.0$ \\
\hline$\$ 5,050$ & $\$ 1,181.5$ & $\$ 1,257.3$ & $\$ 1,333.0$ & $\$ 1,408.8$ & $\$ 1,484.5$ & $\$ 1,560.3$ & $\$ 1,636.0$ & $\$ 1,711.8$ & $\$ 1,787.5$ \\
\hline$\$ 5,300$ & $\$ 1,339.0$ & $\$ 1,418.5$ & $\$ 1,498.0$ & $\$ 1,577.5$ & $\$ 1,657.0$ & $\$ 1,736.5$ & $\$ 1,816.0$ & $\$ 1,895.5$ & $\$ 1,975.0$ \\
\hline$\$ 5,550$ & $\$ 1,496.5$ & $\$ 1,579.8$ & $\$ 1,663.0$ & $\$ 1,746.3$ & $\$ 1,829.5$ & $\$ 1,912.8$ & $\$ 1,996.0$ & $\$ 2,079.3$ & $\$ 2,162.5$ \\
\hline$\$ 5,800$ & $\$ 1,654.0$ & $\$ 1,741.0$ & $\$ 1,828.0$ & $\$ 1,915.0$ & $\$ 2,002.0$ & $\$ 2,089.0$ & $\$ 2,176.0$ & $\$ 2,263.0$ & $\$ 2,350.0$ \\
\hline$\$ 6,050$ & $\$ 1,811.5$ & $\$ 1,902.3$ & $\$ 1,993.0$ & $\$ 2,083.8$ & $\$ 2,174.5$ & $\$ 2,265.3$ & $\$ 2,356.0$ & $\$ 2,446.8$ & $\$ 2,537.5$ \\
\hline$\$ 6,300$ & $\$ 1,969.0$ & $\$ 2,063.5$ & $\$ 2,158.0$ & $\$ 2,252.5$ & $\$ 2,347.0$ & $\$ 2,441.5$ & $\$ 2,536.0$ & $\$ 2,630.5$ & $\$ 2,725.0$ \\
\hline$\$ 6,550$ & $\$ 2,126.5$ & $\$ 2,224.8$ & $\$ 2,323.0$ & $\$ 2,421.3$ & $\$ 2,519.5$ & $\$ 2,617.8$ & $\$ 2,716.0$ & $\$ 2,814.3$ & $\$ 2,912.5$ \\
\hline$\$ 6,800$ & $\$ 2,284.0$ & $\$ 2,386.0$ & $\$ 2,488.0$ & $\$ 2,590.0$ & $\$ 2,692.0$ & $\$ 2,794.0$ & $\$ 2,896.0$ & $\$ 2,998.0$ & $\$ 3,100.0$ \\
\hline
\end{tabular}

Fuente: Elaboración propia

Con la reforma, los optados del SAP salen perdiendo, salvo los pensionados con el DL 1217, tal como ya se mencionó antes.
El sacrificio es mayor mientras más alto es el SBR de los trabajadores, tal como lo confirma la siguiente gráfica. 


\section{Ilustración 22: Reducción de pensión para los optados con 25 años cotizados}

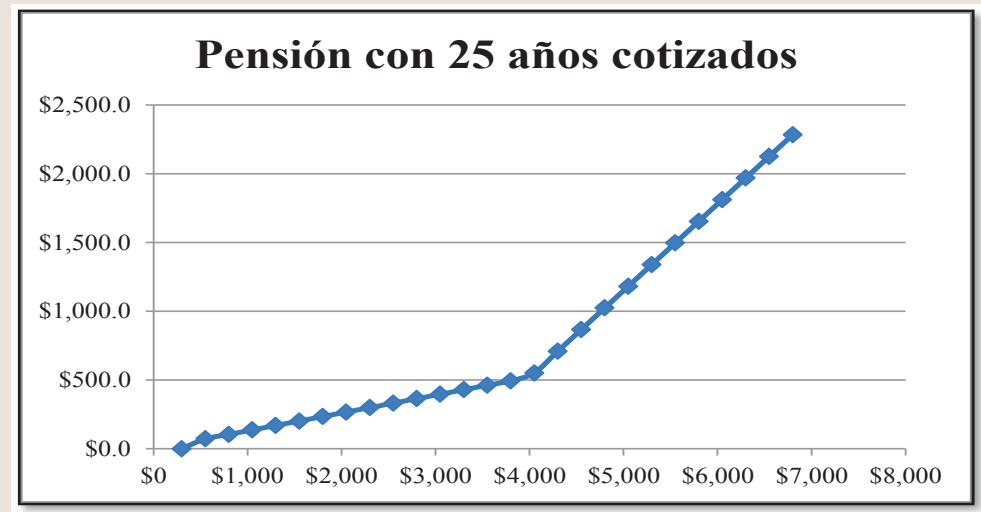

Fuente: Elaboración propia

En el eje de las abscisas se presenta el SBR de los trabajadores y, en el eje de las ordenadas, el valor perdido de la pensión para los afiliados optados; la gráfica muestra que la pérdida de pensión es progresiva, pero gradual, hasta los SBR de $\$ 4,000$, a partir de los cuales la pérdida se dispara de manera verti- ginosa, ya que para ellos la doble restricción a la que nos hemos referido aquí, es severa.

Por si esto no fuera poco, los afiliados pensionados de la franja etaria de optados deberán contribuir a la CSG, en función del monto de la pensión y la pensión mínima vigente.

Ilustración 23: Reducción de pensión para los optados con 25 años cotizados, relacionada con la CGS

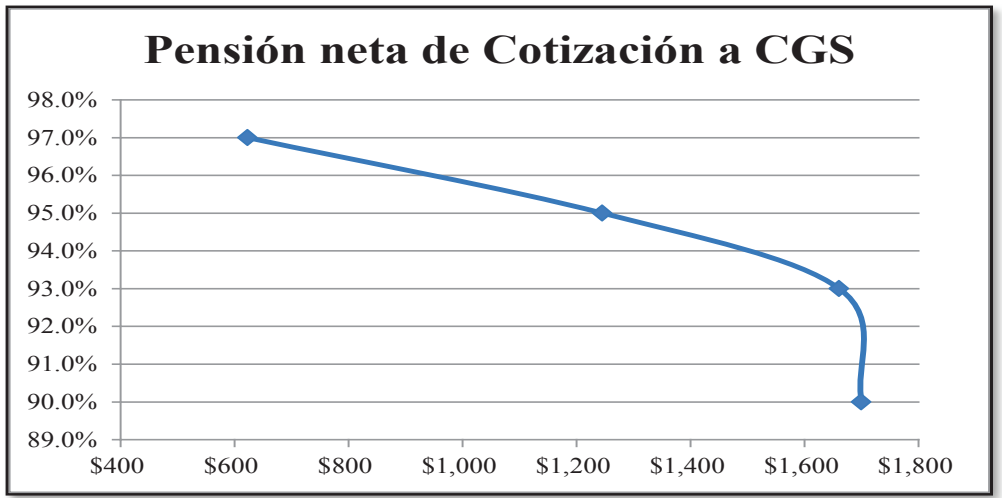

Fuente: Elaboración propia 
A los optados con SBR superiores a $\$ 4,000$, se les descontará $10 \%$ de la pensión para la CGS, es decir, se le entregaría el 90\% de $\$ 2,000$; pero además, deberán cotizar el $7.8 \%$ al ISSS para el régimen de salud y pagarle a la AFP, 1\% del valor de su pensión en concepto de comisión; por ende, recibirán $\$ 1,624$ de pensión líquida.

Al determinar la tasa de reemplazo efectiva para ese SBR, nos daría que asciende al 40.6\%; si sólo se tomara en cuenta el descuento para la CGS, ese indicador sería del 45\%; para SBR superiores, la TR tendería a reducirse, en ambos casos; es decir, descontando la cotización a la CGS, más la aportación al régimen de salud del ISSS.

Los optados saldrán perjudicados claramente con la reforma, teniendo que procurar liquidar sus obligaciones antes de pensionarse para no verse expuestos a perder su vivienda, como está sucediendo con algunos trabajadores en la actualidad; tendrán que ir pensando, probablemente, en trasladarse a vivir con sus hijos para mitigar así la vulnerabilidad económica y social a que han quedado expuestos gracias a esta reforma.

Inclusive los pensionados actuales, amparados al DL 100, verán disminuidas sus pensiones una vez agotado el saldo de sus cuentas y la renta vitalicia a que hacía referencia dicha norma, tenga que ser asumida a través de la CGS.

No obstante lo anterior, los pensionados que permanecieron en el SPP, pero siempre de la franja etaria de los optados, conserva- rán el monto de sus pensiones, lo cual rompe el principio constitucional de igualdad, ya que la equiparación de derechos entre pensionados de ambos sistemas se habría abandonado por completo.

Aquellas personas que creyeron en la iniciativa del Gobierno de 1998 (Ley del SAP) o que por diferentes razones, no llenaron una solicitud de permanencia en el régimen anterior, se verían perjudicados nuevamente, a pesar que fue el mismo Estado el que promovió dicho traspaso, incluso, cambió a los trabajadores de dicha franja etaria, que no habían ejercicio su derecho a permanecer en el régimen especial del SAP, denominado SPP.

La verdad es que la reforma perjudicó a los optados del SAP, incluso a los que se pensionaron con el DL 100.

\section{Resumen}

A manera de resumen, qué se puede decir a partir de este breve análisis de la reforma a la Ley del SAP, aprobada en 28 de septiembre de este año 2017.

- Que la reforma al sistema de pensiones tuvo un carácter esencialmente fiscal.

- Buena parte de la deuda pública relacionada con el sistema previsional se trasladó a los cotizantes mediante la figura de la Cuenta de Garantía Solidaria.

- Otra parte de las obligaciones del Estado, en esta materia, se diluyó al reducir el monto de las pensiones de los opta- 
dos del SAP, incluso de los pensionados al amparo del DL 100.

- La tasa de cotización aumentó, pero debido a la figura de la CGS, el ritmo de acumulación de ahorros se redujo.

- Para compensar dicha contracción, los rendimientos deberían incrementarse sustancialmente, lo cual escapa al control de las entidades gestoras de los Fondos de Pensiones.

- Esto significa que el monto de las pensiones en el SAP serán pequeñas, a pesar que se han ampliado las opciones de inversión.

- Esto es así porque el mercado de capitales en El Salvador es limitado.

- Con la figura del ahorro complementario podría compensarse parcialmente el daño a los derechos de la afiliados, pero sólo para los trabajadores de SBR más altos.

- Se creó la posibilidad de retirar parte del saldo acumulado, antes de pensionarse, pero a condición de postergar la edad de retiro, en caso de no reintegrar ese dinero antes de alcanzar los 60 años de edad, lo cual ocasionará que muchos afiliados no puedan pensionarse oportunamente, aumentando con ello su vulnerabilidad económica y social en la vejez.

- Esta figura del anticipo de saldo, así como otras iniciativas, no están inspiradas en la doctrina de la seguridad social, lo cual dificulta entender cuál es su sentido. Esta última medida parecería estar orientada a desviar la atención del recorte hecho a las pensiones y lograr alguna aceptación de los trabajadores, ya que las necesidades diarias los conduci- rán a tomar estos fondos, sin considerar las consecuencias de esta decisión.

Al cambiar la forma de cálculo de la pensión se elimina el componente actuarial de la gestión, utilizando anualidades ordinarias para determinar el monto de las pensiones.

- Se estableció que las pensiones de vejez corresponde a 20 años de vida, después de pensionarse, lo cual carece de fundamentación en materia de seguridad social.

- La reforma creó una nueva prestación por "longevidad", que tampoco tiene asidero doctrinario, ya que dicho término es consustancial a la vida.

- $\mathrm{Al}$ incorporar ese elemento en la Ley y sufragar las pensiones de las personas que exceden 20 años de vida, en condición de rentistas, con cargo a la CGS, desparece la razón de ser de las Rentas Vitalicias previsionales consignadas en la Ley, porque dichos productos sirven para administrar el riesgo de sobrevivir más allá del saldo acumulado para la vejez (longevidad).

- Se reducen las pensiones por sobrevivencia, al bajar la pensión de referencia para efectos de cálculo.

- Por ende, también deberían disminuir los capitales complementarios a pagar por eventos de invalidez y fallecimiento común.

- De ser así, las comisiones netas por la administración de las cuentas de ahorro para el retiro se elevarían.

- A los afiliados optados del SAP, pensionado conforme al DL 1217, le crearon derechos adicionales de manera sor- 
prendente, a pesar que el Estado ya les había reconocido el derecho a la equiparación de pensiones, previamente, con base al referido decreto, trasladándole la obligación de pagarlos a la CGS, es decir, a los afiliados al SAP.

- Con la reforma se preservaron las prestaciones de los optados que permanecieron en el SPP, a pesar de tratarse de la misma población, entrando en contradicción con el principio constitucional de igualdad.
- Las pensiones netas máximas para los optados del SAP serán de $\$ 1,624$, considerando la doble restricción impuesta por el legislador, de bajar la tasa de remplazo máxima hasta el $55 \%$ y el valor absoluto de la pensión, a $\$ 2,000$.

- A dicho valor habría que restar la cotización al régimen de salud del ISSS (7.8\% de la pensión) y la aportación a la CGS, que sería del $10 \%$ para dichas pensiones; menos otro $1 \%$ de comisión para la AFP; es decir que, a la pensión máxima deberá descontársele el $18.8 \%$ de su valor.

\section{Referencias bibliográficas}

1 Asamblea Legislativa, Ley del Sistema de Ahorro para Pensiones, 1996.

2 Asamblea Legislativa, Decreto 1217, Ley de Equiparación de Pensiones, 2003.

3 Asamblea Legislativa, Decreto 98, Ley del Fideicomiso de Obligaciones Previsionales, 2006.

4 Asamblea Legislativa, Decreto 100, Reforma a la Ley del Sistema de Ahorro para Pensiones, 2006.

5 Asamblea Legislativa, Decreto 787, Reforma a la Ley del Sistema de Ahorro para Pensiones, 2017.

6 CASTILLO, Rodolfo, estimaciones actuariales de las propuestas de reforma al Sistema de Ahorro para Pensiones, 2017.

7 Ministerio de Hacienda, presentaciones de la propuesta de sistema mixto, 2013.
8 SORTO RIVAS, Francisco, PENSIONES DE VEJEZ PARA ENFERMOS TERMINALES, Editorial Académica Española, España 2011. 978-3-8465-7738-7

9 SORTO RIVAS, Francisco, Rentas Vitalicias vinculadas a Sistemas de Capitalización Individual de Pensiones, ISEADE, El Salvador, 2015. 978-99923-62-32-7

10 SORTO RIVAS, Francisco, sistema previsional PARA EL SALVADOR: política pública de pensiones y calidad de derechohabientes de sus usuarios, ISEADE, EI Salvador, 2015. 978-99923-62-33-4

11 SORTO RIVAS, Francisco, SISTEMAS DE PENSIONES DE CAPITALIZACIÓN INDIVIDUAL Y LA EXPERIENCIA DEL IPSFA, ISEADE, El Salvador, 2016. 978-99961-0$683-5$ 